\title{
LA PERSONALIDAD PSICOPATICA EN NIÑOS Y SUS POSIBLES IMPLICACIONES. UN ANALISIS PROSPECTIVO DESDE LA TEORIA DE ROBERT HARE
}

\section{ARTÍCULO ORIGINAL}

MACHADO, Daniel Dias ${ }^{1}$, KAWAKAM, Roland ${ }^{2}$

MACHADO, Daniel Dias. KAWAKAM, Roland. La personalidad psicopatica en niños y sus posibles implicaciones. Un analisis prospectivo desde la teoria de Robert Hare. Revista Científica Multidisciplinar Núcleo do Conhecimento. Año 06, Ed. 07, Vol. 08, págs. 112 y 162. Julio de 2021. ISSN: 2448-0959, Enlace de acceso: https://www.nucleodoconhecimento.com.br/psicologia-es/personalidad-psicopatica, DOI: $\quad 10.32749 /$ nucleodoconhecimento.com.br/psicologia-es/personalidad-

psicopatica

\section{RESUMEN}

Desde hace algún tiempo, la psicopatía se considera como una entidad clínicamente controvertida, sin embargo, las últimas investigaciones indican que es una entidad clínica necesaria y que puede ser útil para la sociedad en general por su gran valor predictivo de la repetición de conductas delictivas, violentas y de abuso sexual pero la psicopatía infantil además apoyará en el diagnostico tratamiento y mejoría de

\footnotetext{
${ }^{1}$ Tecnólogo em Comércio Exterior pelo Instituto Brasileiro de Gestão Empresarial (IBGEN) de Porto Alegre, Paralegal em Conciliação, Mediação e Arbitragem pela Crown University of Bradenton, Bacharel em Ciências Jurídicas Estrangeiras pela Crown University of Bradenton, Tecnólogo em Serviços Jurídicos e Notariais pelo Instituto Brasileiro de Treinamento (IBF) de Joinville e Bacharel em Psicologia pela Escola Superior Batista do Amazonas (ESBAM). Da mesma forma, completou duas especializações, em Criminologia na Faculdade Famart de Itaúna e em Ética e Justiça na Harvard University em Massachusetts. Possui Mestrado em Administração com Menção em Gestão Organizacional pela Universidad Nacional Experimental de Los Llanos Occidentales Ezequiel Zamora de Santa Bárbara, Doutorado em Ciências Jurídicas pela Crown University de Bradenton e Pósdoutorado em Aplicação da Ontologias para Gestão do Conhecimento pela Crown University de Bradenton na condição de dupla diplomação com o programa de Pós-doutorado em Ontologia do Conhecimento e sua Transcendência da Perspectiva Educacional, e sua aplicação na Gestão Organizacional pela Universidade Fermín Toro de Lara.

${ }^{2}$ Orientador.
}

RC: 91661

Disponível em: https://www.nucleodoconhecimento.com.br/psicologiaes/personalidad-psicopatica 
caracteristicas y rasgos que puedan presentar como muestra de una conducta psicopatica incipiente en niños y jovenes a traves de teorías o instrumentos de medición como los expresados por Robert Hare. De allí que la presente investigación documental, a traves de las tecnicas de recolección de datos bibliograficos busque como objetivo general Analizar la personalidad psicopatica en niños desde la perspectiva de la teoría de Robert Hare y a traves de la estructura metodologica hermeneutica realizar un analisis, conclusiones o recamendaciones que a futuro logren disminuir los casos de extrema violencia qe se reflejan a diario en nuestra sociedadpor causa de personas psicopatas.

Descriptores: Psicopatia Infantil, Implicaciones, Robert Hare.

\section{INTRODUCCIÓN}

El estudio de los rasgos psicopáticos en la infancia adquiere gran interés si se toma en cuenta que éstos pueden ser factores de riesgo de psicopatología en la infancia, la adolescencia y luego la adultez. Algunos autores han relacionado la manifestación temprana de dichos rasgos con una peor evolución de los trastornos de conducta, encontrándose, por ejemplo, la influencia de ciertos rasgos afectivos (insensibilidad o dureza emocional, ausencia de culpa, insensibilidad al castigo) en un peor pronóstico, mayor persistencia y severidad de dichos trastornos.

La presente investigación trata de definir al niño, abordando la cuestión del síntoma en el niño de psicopatía, caracteristicas y sus posibles implicaciones. Es sabido que frente a otras especies animales, el niño nace en un estado de prematuración, sus procesos de mielinización están inacabados, su desarrollo y coordinación psicomotriz son absolutamente insuficientes, no existe un yo unificado que permita dar cuenta de esas sensaciones dispersas que se mueven en la dialéctica del placer-displacer. El bebé está en una situación de impotencia radical, es un objeto a cuidar, a alimentar por alguien que en contrapartida, está en una situación de omnipotencia. Digamos que, desde aquí, el bebé está en posición de un algo que

RC: 91661

Disponível em: https://www.nucleodoconhecimento.com.br/psicologiaes/personalidad-psicopatica 
puede acceder, o no, a un alguien. Acceso que se rige desde una correcta posición en lo simbólico; posición, que, de entrada, aún antes de que se desarrolle, está presente ya. Porque el niño es pensado, hablado, situado en una historia o en una encrucijada de historias, antes de nacer.

Este es el mundo simbólico que lo precede y en el que se inserta; justamente se convierte en sujeto por insertarse en el mundo simbólico. En él están presentes las cartas de la baraja con las que podrá jugar en la vida; habrá cartas repetidas, rotas o faltantes; en cualquier caso, un repertorio limitado para jugar la partida de la vida.

De allí que la presente investigación busca identificar las implicaciones que puede tener el comportamiento psicopatico en los niños y jovenes.

El trabajo de grado está distribuido de la siguiente manera: En el Capítulo I, se denomina El Problema, donde se ubica el Planteamiento del Problema, formulación del problema, Objetivos de la Investigación, Justificación e importancia. El Capítulo II, se organizó tomando en consideración los Antecedentes de la Investigación y bases teóricas. El Capítulo III, contiene la metodología utilizada, es decir, la naturaleza de la investigación, como también las Técnicas e Instrumentos para la Recolección de la Información y demás técnicas operacionales para el manejo de la información.

Una vez cumplida con esta fase de la investigación, se realizó el Capítulo IV que contiene analisis del contenido más relevante de lo estudiado, las conclusiones y recomendaciones y posteriormente se hace mención a las referencias bibliograficas que se utilizaron en el transcurso de la investigación.

\section{EL PROBLEMA}

\section{PLANTEMIENTO DEL PROBLEMA}

RC: 91661

Disponível em: https://www.nucleodoconhecimento.com.br/psicologiaes/personalidad-psicopatica 
En el campo de la psiquiatría, la psicopatía en adultos es un tema que ha sido muy estudiado. Es así que en los últimos veinte años se han tenido desarrollo en su definición, la forma de evaluarla y el tratamiento de esta enfermedad mental. En el área infantil se conoce poco de su desarrollo, tampoco se ha estudiado la forma de identificarla en niños.

En esta tesis se realiza una revisión de la literatura existente sobre la psicopatía en la infancia y la adolescencia. Se propone una investigación en la línea de Lynam quien mantiene que existe relación entre hiperactividad y problemas conductuales. También con el autor Frick quien establece un avance en el modelo bifactorial de Hare a los niños y jóvenes. adolescencia). Y por último, no menos importante se expone la perspectiva de Rogers como humanista que presenta teorias de como a traves de la terapía los niños pueden mejorar estas condiciones y cambiar su futuro.

A pesar del interés que ha despertado la psicopatia, y a pesar de que se generado mejoras en su diagnóstico y valoración y en la clarificación de su naturaleza, todavia se sabe poco sobre sus antecedentes evolutivos. El término psicopatia se reserva habitualmente para adultos, y el DSM-IV no permite el diagnóstico de TAP antes de los 18 años. Sin embargo, la mayor parte de los clinicos y los investigadores probablemente consideran de la misma forma las propiedades personales y de conducta de la psicopatía no aparecen súbitamente en la adultez, sino que se manifiestan en etapas mas tempranas de la vida (FORTH Y BURKE, 1998).

La detección temprana de la psicopatia es muy importante. Ya que su diagnóstico y su evolución en el tratamiento ha presentado muchos problemas. Su prevención en edades iniciales ha probado resultados interesantes y él debe disponerse de herramientas que permitan la identificación de jóvenes con mayor riesgo de desarrollar una personalidad y una conducta psicopática.

A lo largo de la historia, se han dado ejemplos de aplicación del concepto psicopatia a jóvenes. Ya en 1909 se creaba en Chicago el llamado Instituto Psicopatico Juvenil (WORK, 1994), si bien bajo el término psicopático se incluyen los cambios

RC: 91661

Disponível em: https://www.nucleodoconhecimento.com.br/psicologiaes/personalidad-psicopatica 
emocionales y de conducta, además de incluir los trastornos antisociales. Luego, algunos investigadores experimentaron con adolescentes entre los intervalos de edades que van desde los 13 hasta los 18 años, tratando de demostrar que sus datos experimentales en psicópatas adultos. podrian generalizarse a poblaciones jóvenes y si, por tanto, el constructo de psicopatia juvenil tenia visos de validez.

El esquema de la construcción de la psicopatía juvenil ha recibido esfuerzos más sistemáticos en los últimos años. Nos encontramos ante un campo que está adquiriendo especial dinamismo y que, en nuestra opinión, presenta un alto interés tanto por sus implicaciones teóricas como por sus prácticas se volcaron hacia la intervención con problemas menores.

Sin embargo, a pesar de la actividad que se esta generando en torno a este tema, las distintas lineas se han desarrollado de forma fragmentaria y paralela, con escasos puntos de contacto, y se echan de menos esfuerzos que permitan ordenarlas, compararlas e integrarlas, y que exploren sus aportaciones y sus limitaciones.

Los autores que trabajan en estas lineas más actuales parten de la convicción de que las caracteristicas psicopáticas pueden ser identificadas en sujetos adolescentes confiables y que también coexiste un reducido subgrupo de niños que muestran indicios tempranos de psicopatia; un conocimiento exhaustivo de los mecanismos que subyacen a la conducta de estos infantes se aplicara para rutas de mediación que adviertan cambios comportamentales importantes.

Tal como lo indica Frick (1998), varios autores no están de acuerdo con la definición del concepto de psicopatía en infantes. Unos no se ponen de acuerdo en el diagnóstico y su tratamiento. Otro grupo tienen miedo sobre el influjo del entorno social del infante en el desarrollo de su temperamento.

Según el autor Frick previamente citado, estos temores deben ser rechazados porque no se puede comparar los resultados obtenidos en sujetos adultos con su

RC: 91661

Disponível em: https://www.nucleodoconhecimento.com.br/psicologiaes/personalidad-psicopatica 
aplicación en los infantes. No se debe además disminuir el valor del contexto social en el crecimiento de los niños de su personalidad como los psicopáticos.

Frick advierte además, que el uso del concepto de psicopatía en infantes es suponer que todos los niños con grandes problemas conductuales exhiben estas conductas tempranas de psicopatia (RICHTERS Y CICCHETTI, 1993), cuando, esta no parecer ser la realidad.

Para examinar las raices de la psicopatia adulta debemos centrar la mirada en una categoria diagnóstica que, de un modo explicito, en el DSM se contempla como un requisito para el diagnóstico del TAP: el trastorno de conducta o trastono disocial.

En efecto, la investigación ha constatado una innegable prolongación de sus comportamientos en la infancia y la conducta antisocial adulta (ROBINS, 1966), de modo que los adultos antisociales suelen tener una historia de alteraciones de conducta en la niñez. Sin embargo, también es cierto que la mayoría de los niños con perturbaciones de conducta se transformen en delincuentes. La continuidad de las perturbaciones de conducta usando las razones DSM, es superior que las del TAP y el avance de la psicopatía relacionada con el PCL parece reducirse. Esto indica que del trastorno de conducta presenta gran diversidad y que un solo numero reducido de niños pueden establecerse con este riesgo de psicopatía.

Entre otro de los estudiosos de la psicopatía, se encuentra, Robert Hare quien fue uno de los mayores expertos internacionales en este campo é describió a los sujetos con tendencia psicópatas "caníbales" que usan el encantamiento, el manejo y los actos de violencia para manejar a los seres humanos y poder satisfacer sus deseos. Con su mente perturbada cometen delitos sin conciencia y sin remordimento o sentimientos de culpabilidad, Básicamente todos hemos sido víctimas en algún momento de nuestra vida de la conducta de estos psicópatas. En todas las esferas mundiales del delito, ráfico de sustancias ilícitas, asesinatos, contrabando, estafa, corrupción política, guerra, etc.

RC: 91661

Disponível em: https://www.nucleodoconhecimento.com.br/psicologiaes/personalidad-psicopatica 
Tomando en cuenta lo anterior, es probable que se puedan tambien identificar si existen niños o adolescentes que luego de ser detectados con rasgos de psicopatía infantil puedan revertir esa situación y convertirse en adultos sanos a traves de las terapías propuestas por Hare. Es de este planteamiento que surgen las siguientes interrogantes ¿Es posible que los niños puedan presentar sintomas de psicopatía?; ¿Que caracteristicas tendrían los niños con personalidad psicopatía?; ¿Cuales serían las implicaciones de la personalidad pscicopatica en niños?, ¿La teoría de Hare presenta alternativas para intervenir la posible psicopatia en niños? Las siguientes interrogantes seran respondidas en los objetivos de la investigación.

\section{OBJETIVOS DE LA INVESTIGACIÓN}

\section{OBJETIVO GENERAL}

Analizar la personalidad psicopatica en niños desde la perspectiva de la teoría de Robert Hare.

\section{OBJETIVOS ESPECIFICOS}

1. Determinar la probabilidad de que los niños puedan presentar sintomas de psicopatía.

2. Caracterizar los sintomas de que tendrían los niños con personalidad psicopatíca.

3. Definir las implicaciones que traería en la adultez presentar razgos de personalidad pscicopatica en la niñez.

\section{JUSTIFICACIÓN DE LA INVESTIGACIÓN}

Las enfermedades mentales, entre ellas la psicopatía, son las enfermedades más graves en cualquier sociedad, no solo por la gravedad y violencia del comportamiento que produce, sino también porque requiere el uso de diversos 
servicios que van desde las cárceles y los sistemas judiciales hasta los sistemas de justicia, salud mental y cuidado de la salud.

Entre las funciones primordiales de las teorías que explican la psicopatología, se encuentra el predecir cuales son esas personas propensas a presentar conductas altamente perturbadoras. La incomprensión de este fenómeno que trata de explicar actos violentos graves, hace que los individuos releguen a estas personas indicando que "son malos, malvados", y se realice la siguiente interrogante ¿Cómo una persona podría matar, violar, robar o agredir, de manera repetida a otros individuos, si no es por una fuerza maligna? A pesar, que estos actos realizados por los individuos son considerados "malignos", quienes los cometen son seres humanos. En tal sentido, los psicópatas no son "diferentes" de nosotros, sino que presentas características extremas de los seres humanos.

Por ello, Hare sostiene la idea que dichos individuos tienen características propias como que experimentan emociones lábiles y superficiales, no son empáticos, tienen ansiedad y sentimientos genuinos de culpa y remordimiento, son incapaces de establecer vínculos estables con otros individuos. Al hacer referencia su conduta, se puede indicar que son irresponsables, impulsivos y, en este mismo sentido, buscan nuevas sensaciones, por lo que les es fácil transgredir las normas sociales, otra característica es que su estilo de vida es inestable ya que incorpora comportamientos parasitarios y sin planificación.

Se justifica la presente investigación ya que por medio del conocimiento de la caracteristicas y las teorias que apoyan la existencia de la psicopatía en niños y adolescentes se pueden prevenir comportamientos indeseados, ahora bien ise presenta la psicopatía en poblaciones infantiles y adolescentes? En opinión de algunos autores, los rasgos psicopáticos aparecen en la adolescencia en todos los individuos y no son más que aspectos normales que tienden a desaparecer (SEAGRAVE Y GRISSO, 2002). Sin embargo, otro grupo importante de investigadores, aunque están de acuerdo con la aseveración anterior, indican que

RC: 91661

Disponível em: https://www.nucleodoconhecimento.com.br/psicologiaes/personalidad-psicopatica 
los signos de la psicopatía son detectables en los niños y representan algo mas que una manifestación normal correspondiente a una etapa del desarrollo (JOHNSTONE Y COOKE, 2004).

A pesar de lo indicado en el párrafo anterior, se deben tener claras las características evolutivas propias del niño o del adolescente, se debe considerar que algunos síntomas asociados a la psicopatía se presentan en la adolescencia como una etapa evolutiva más, por lo que se corre el riego de diagnosticar falsos positivos, sin embargo, existen datos que permiten indicar las características psicopáticas a edad temprana, y eso es importante para la prevención, desarrollando de esta manera estrategias de intervención acordes para este tipo de jóvenes, de allí la relevancia de la presente investigación.

Es decir, estos niños y adolescentes son "diferentes" a los niños normales, se puede indicar que son más difíciles de tratar, agresivos, traviesos y mentirosos, no se relacionan fácilmente o les es difícil acercarse a otros niños, buscan la manera de desafiar las normas y la autoridad. En este grupo de niños con problemas de conducta, el cual es grande y heterogéneo, se debe diferenciar aquellos que presentan un elevado comportamiento antisocial en el cual desafían constantemente la autoridad y las normas pero que además son sujetos fríos, manipuladores, mentirosos y tienen dificultad a la hora de experimentar determinadas emociones, como el miedo, por lo cual no aprenden de los castigos y son difíciles de socializarles.

Esto niños y adolescentes necesitan un atención especial y diferenciada ya que no es solo el problema conductual, sino que presentan rasgos de personalidad asociados a la falta de seguimiento de normas (frialdad emocional, manipulación, falta de empatía, por mencionar algunos), por lo cual son problemáticos para la sociedad.

En la década de los noventa comenzó el interés por estudiar y evaluar la psicopatía infanto-juvenil, por lo que se generó la necesidad de diseñar una herramienta que

RC: 91661

Disponível em: https://www.nucleodoconhecimento.com.br/psicologiaes/personalidad-psicopatica 
pudiera ser aplicada a esta población, ya que las existentes hasta esa fecha eran aplicables sólo a la población adulta. Entre los instrumentos mas empleados se encuentran los desarrollados por Robert Hare.

Un reto a futuro se encuentra centrado en el tratamiento de esta población. Existe un consenso en la mayoría de los autores relacionados con el tema, donde no se ha demostrado que exista algún tipo de intervención que resulte exitosa en estos individuos, sin embargo, cada día se presentan mas estudios que demuestran la presencia de este trastorno en etapas infantiles, por lo cual, es la dirección correcta del estudio. Kochanska (1997), resaltó en su investigación la importancia de valorar el temperamento del infante, indica en su estudio que los niños "poco temerosos" pueden presentar dificultades severas para el desarrollo de emociones morales como la culpa o la empatía, lo cual incide directamente el desarrollo de la moral del menor. Es por ello que la investigación se reviste de importancia desde el punto de vista social, educativo, psicologico, legal, y metodologico.

\section{MARCO TEORICO}

\section{ANTECEDENTES HISTORICOS}

Desde inicios de los extensos períodos históricos la terminación "psicopatía" ha originado una gran cantidad de polémica (TORRUBIA Y FUENTES, 2008). Dicho acontecimiento al generar un debate universal entre los profesionales de las diferentes áreas, justicia, salud y seguridad, junto con aquellos que forman parte de la urbe debe poder comprenderse desde lo más básico, examinando las diferentes etapas de la expresión psicópata o sociópata, partiendo del origen y prosiguiendo con el desarrollo o evolución

El comienzo de los descubrimientos sobre la psicopatía parten del siglo XVII, época en la cual se empezaba a discutir sobre individuos que accionaban y concebían las emociones distintivamente en comparación con otros (CABELLO Y BRUNO, 2009) A medida que avanzaba el tiempo se implementaba el término "manía” para referirse al

RC: 91661

Disponível em: https://www.nucleodoconhecimento.com.br/psicologiaes/personalidad-psicopatica 
actuar de acuerdo al concepto de un psicópata, no fue hasta inicios del siglo XIX que un francés, Philippe Pinel distinguió la manía en dos subdivisiones, con delirio y sin delirio, definiendo a aquella sin delirios a la afectación emocional e iniciativa compulsivo-agresiva direccionada a sucesos violentos sin la presentación de variaciones intelectuales (CABELLO Y BRUNO, 2009; TORRUBIA Y FUENTES, 2008; POZUELO; ROMERO Y CASAS, 2011)

Posteriormente en el año 1835, Pritchard introdujo a Inglaterra el nuevo concepto "locura moral" para la descripción del trastorno afectivo conductual sin delirios y con completo e incólume desempeño docto, realzando la inhabilidad de acatar reglamentos (CABELLO Y BRUNO, 2009; TORRUBIA Y FUENTES, 2008; POZUELO et al., 2011). Años después Morel en 1850, infirió que la significación de la palabra psicopatía era un deterioro cerebral producido por alguna enfermedad genética la cual perjudica netamente la función decorosa. En 1881 Koch, introduciendo por primera vez la palabra en sí, describe a la psicopatía de dos maneras: el sufrimiento autoinfligido y el daño a externos, refiriéndose a él como subordinaciones psicopáticas (CABELLO Y BRUNO, 2009; MARIETÁN, 2000; RONSON, 2012)

Seguidamente en 1896, Kraepelin comienza a visualizar a la psicopatía como un trastorno o desequilibrio de la personalidad. Sin embargo, fue Schneider en 1923 quien desarrolló dicho desorden como una representación de una manera de vivir desalmada en la cual "aquel que por su anormalidad sufre o hace sufrir a los demás" (p.17). Haciendo que Schneider llegue a la conclusión de que existen hasta el momento diez subtipos de trastornos de la personalidad psicopática: hipertímicos, melancólicos, temerosos, fanáticos, presuntuosos, frágiles, explosivos, indiferentes, apáticos, exinanidos (CABELLO Y BRUNO, 2009; TORRUBIA Y FUENTES, 2008; POZUELO et al., 2011; POZUELO, 2011)

Más adelante, en 1941 con la publicación del libro "la máscara de la cordura" de Cleckley se adquiere un nuevo empujón y avivamiento por la presentación 
fenomenológica interior y exterior del desorden psicopático de la personalidad, causando interés entre los profesionales de la salud. En la obra referente se ejecuta la distinción inaugural entre individuos criminales y personas que padecen de psicopatía funcional, además se reconoce que aquellos afectados son capaces de reproducir las emociones y acciones morales correspondientes al ser humano normal, finalmente se realiza una diferenciación de la conciencia con decoro e intelectualidad donde queda claro que los psicópatas tienen una cognición intelectual indemne a costa de una cognición moral perjudicada, ya que dicen algo pero realizan otra cosa. (CABELLO Y BRUNO, 2009; TORRUBIA Y FUENTES, 2008; POZUELO et al., 2011; POZUELO, 2011; HARE, 1999; BECK; FREEMAN Y DAVIS, 2005)

Entre las características clínicas que presenta el psicópata (CLECKLEY, 1998), se encuentran: (a) encanto superficial y buena inteligencia; (b) ausencia de delirios u otros signos de pensamiento irracional; (c) ausencia de nerviosismo o manifestaciones psiconeuróticas; (d) poca fiabilidad, falsedad o falta de sinceridad; (e) alta de remordimiento o vergüenza; ( $f$ ) conducta antisocial sin un motivo que la justifique; (g) juicio deficiente y dificultad para aprender de la experiencia; (h) egocentrismo patológico e incapacidad para amar; (i) pobreza generalizada en las principales relaciones afectivas e insensibilidad en las relaciones interpersonales; (j) perdida específica de la intuición; ( $k$ ) conducta extravagante y desagradable bajo los efectos del alcohol o sin él; (I) amenazas de suicidio raramente consumadas; (m) vida sexual impersonal, frívola y poco estable; $(n)$ incapacidad para seguir su propio plan de vida (MARIETÁN, 2000).

Luego de esto, el profesor Robert Hare uso las características definidas por Cleckley y en 1991 realizó un instrumento que sirve para diagnosticas la psicopatía, le colocó el nombre de Psychopathy Cheklist (PCL), posteriormente fue revisada en el 2003, y se le incluyó participantes femeninas. El valor diagnóstico y predictivo de este instrumento ha sido comprobado en múltiples investigaciones, por lo cual se le da

RC: 91661

Disponível em: https://www.nucleodoconhecimento.com.br/psicologiaes/personalidad-psicopatica 
una identidad clínica estable a la psicopatía por primera vez en la historia, y es el enfoque que se utilizará para la comprensión en la presente investigación.

\section{BASES TEORICAS}

\section{PSICOPATÍA}

Existe consenso en la comunidad científica de que la psicopatía es un constructo que presenta relevancia clínica y criminológica. Los estudios epidemiológicos muestran que una gran proporción de los delitos son ejecutados por una minoría de delicuantes, pero estos son persistentes (FARRINGTON; OHLIN Y WILSON, 1986) por lo que se considera que los psicópatas constituyen una parte importante de dicha minoría. Últimamente las investigaciones relacionan a la psicopatia con indicadores de una carrera criminal, cronificada y severa: la psicopatia se ha relacionado con una mayor tasa de delitos y una mayor versatilidad (HARE; MCPHERSON Y FORTH, 1988), mayores cifras de reincidencia (SALEKIN; ROGERS Y SEWELL, 1996), de crimenes violentos (HART, 1998) y de agresiones sexuales graves (BARBAREE et al., 1994), asi como una pobre respuesta al tratamiento (LOSEL, 1998).

A pesar de la importancia del tema, la psicopatía es un constructo controvertido, con una historia larga y un tanto complicada. En términos breves, se han venido identificando dos grandes tradiciones en el análisis de la psicopatia (ALUJA, 1989; LUENGO Y CARRILLO, 1995). Se puede mencionar el perfil de la personalidad como una de ellas, cuyo origen nace en la tradición y la práctica clínica, allí se agrupan características tales como la falta de empatia, las dificultades para la planificación, los déficits afectivos, el egocentrismo o la falta de remordimientos. Esta tradición estaría se encuentra representada por investigadores clásicos como Cleckley (1940), siendo sistematizada, en parte, por los criterios de la personalidad disocial, de la CIE (OMS, 1992).

RC: 91661

Disponível em: https://www.nucleodoconhecimento.com.br/psicologiaes/personalidad-psicopatica 
Otro movimiento tradicional es el neo-kapreliano en psicodiagnóstico, este tiene su origen en la Universidad de Washington y presenta una caracterización básicamente conductual del trastorno. Por su parte Hart y Hare (1997), señalan dentro de sus postulados, que la evaluación debería estar centrada en medir comportamientos observables, ya que los clínicos es poco probable que permitan hacer una evaluación fiable de las características personas o afectivas. Esta tradición queda bien reflejada en las últimas versiones del DSM. A diferencia de lo que ocurria en el DSM-I y, sobre todo en el DSM-11, las características de personalidad carecen de protagonismo en el llamado trastorno antisocial de la personalidad, (TAP) descrito por el DSM-111; los indicadores de una conducta antisocial sostenida son el centro de atención, por lo tanto permite obtener una descripción con buenos niveles de consistencia interjueces, aunque, algunos opinan que se desvirtúa la noción clínica original de la psicopatía (HARPUR; HART Y HARE, 1993).

A pesar de ello, en el DSM-111-R y en el DSM-IV observamos algunos cambios, entre ellos el intento por incluir descriptores personales, aunque el resultado no dejó satisfecho a los clínicos y el peso fundamental del diagnóstico sigue recayendo en una historia de conducta antisocial reiterada.

Las discusiones sobre la problemática conceptual de la psicopatía se han presentado en las últimas décadas, se puede mencionar a Millon y Da vis (1998), el cual identificó 10 variantes del trastorno. Pero, es de destacar que últimamente se presenta una concepción que ha ganado consenso, donde confluyen aspectos personales y conductuales, esta es la propuesta de Hare (1980); Casi al mismo tiempo que aparecian los criterios del DSM-IV, Hare desarrolló un sistema alternativo para evaluar la psicopatía en aquellos delincuentes institucionalizados: el PCL (Psychopathy Checklist), las cuales se han aplicado por observadores expertos, el trabajo se basa en entrevistas semiestructuradas y la revisión del historial del caso. Instrumento (PCL-R) consta de 20 items en su última versión, puntuadas en una escala de 3 puntos (desde 0 hasta 2) en función del grado en que cada item es

RC: 91661

Disponível em: https://www.nucleodoconhecimento.com.br/psicologiaes/personalidad-psicopatica 
aplicada a cada individuo; por lo tanto, se toma una puntuación de 30 como criterio para diagnosticas la psicopatía.

En las investigaciones, donde se ha empleado este instrumento, se ha definido una estructura de dos factores, las cuales captarian, respectivamente, los aspectos de personalidad y de conducta del constructo psicopatia (MOLTÓ; POY Y TORMBIA, 2000). El Factor 1 se define por característica propias de esos individuas como el egocentrismo, la falta de sinceridad, insensibilidad y falta de remordimiento, estos describen la configuración personal que tradicionalmente caracteriza al psicópata desde la tradición clínica. El segundo factor caracteriza los aspectos del constructo relacionados con la conducta desviada y un estilo de vida crónicamente inestable y antisocial. Se han encontrado evidencias de la validez discriminante de estos factores. Por lo tanto, el factor 1 tiene relación mas estrecha con los criterios de Cleckley y con medidas autoinformadas de ansiedad, empatía (Correlación negativa), narcisismo y dominancia (correlación positiva). Por otro lado el factor 2 , se encuentra mas relacionado con el diagnóstico TAP del DSM y, con signo negativo, con otras variables como el estatus socioeconómico, el nivel educativo o la inteligencia.

Ambos factores están correlacionados entre si (con indices en torno a SO), si bien es posible obtener una alta puntuación en un factor y baja en el otro. Esto se correspondería con el hecho de que, como señala el mismo Cleckley, no todos los psicópatas definidos por los criterios tradicionales dan respuesta al diagnostico de TAP, ni todos los individuos con TAP podrían considerarse psicópatas.

Como muestra de lo anterior, existen hallazgos en las poblaciones de delincuentes institucionalizados, que indican tasas de TAP en torno al 75\%; en este sentido, las tasas de psicopatia definidas por el PCL en estas poblaciones se sitúan en torno al $30 \%$ (HART Y HARE, 1989) y se han encontrado algunas cifras con valores menores. Existen diferentes planteamientos sobre los mecanismos que explican la psicopatía, esta falta de claridad conceptual entorpece el avance en este campo de

RC: 91661

Disponível em: https://www.nucleodoconhecimento.com.br/psicologiaes/personalidad-psicopatica 
estudio. En este orden de ideas, en las investigaciones mas desarrolladas cabe citar la formulada, bajo la inspiración teórica del modelo de Gray, por autores como Fowles 1980), para quien la psicopatia se aproxima a un débil Sistema de Inhibición Conductual (BIS; Behavioral Inhibition System), un sistema que, en el modelo de Gray, regula la dimensión de ansiedad.

De manera similar, Lykken propone hace algunas décadas (LYKKEN, 1957) que una característica de la psicopatía son los déficits a la hora de experimentar ansiedad o miedo (Esta hipótesis se llama de bajo miedo; low fear hypethesis). Desde esta corriente del estudio, se ha propuesto que tres factores oblicuos (y no dos) podrian representar mejor el constructo psicopatia del PCL-R. Cooke y Michie (1999), haciendo uso de técnicas de analisis factorial confirmatorio, plantean que el factor identificado en los estudios de Hare podría seccionarse en dos.

Propiamente, la psicopatia primaria seria la asociada a un debil BIS. De acuerdo con diversos autores (LYKKEN, 1995) existiria una psicopatia secundaria, caracterizada por un BIS normal, pero por un BAS (Sistema de Activación Conductual) muy activo, desarrollando abundante evidencia experimental sobre los déficits en evitación pasiva de los psicópatas. Los sujetos tienen dificultades para inhibir aquellas respuestas que tienen implícito un castigo. También relacionada con estas posiciones los desarrollos de Newman (NEWMAN Y WALLACE, 1993).

Los hallazgos de este autor sugieren que los psicópatas muestran dificultades para modular sus respuestas, es decir, para responder a las contingencias ambientales, asimilar el feedback del ambiente y cambiar una tendencia (set) de respuesta establecida; en tareas de laboratorio como la del juego con barajas los sujetos de estrudio deben tomar decisiones como si sigue jugando a pesar de estar perdiendo su dinero, en el caso de los psicópatas son perseverantes, ellos siguen jugando a pesar de tener una respuesta asociada al castigo.

Existen otras corrientes investigativas que develan los problemas que tienen los psicópatas para manejar y procesar la información, tanto verbal como no verbal,

RC: 91661

Disponível em: https://www.nucleodoconhecimento.com.br/psicologiaes/personalidad-psicopatica 
que presenta contenido emocional (HARE; WILLIAMSON Y HARPUR, 1988; PATRICK, 1994). De esta manera, las investigaciones psicofisiológicas tradicionales, que se han enfocado en las relaciones que tienen la psicopatia y una baja activación cortical (RAINE, 1989), y lineas neuropsicológicas que han propuesto déficits en las funciones ejecutivas (GORENSTEIN, 1982). Es importante mencionar los estudios realizados por la neuroimagen, donde se demuestran las disfunciones en áreas prefrontales, así como en otras zonas, entre ellas el cuerpo calloso o el giro angular izquierdo (RAINE, 1999). Determinando trastornos psicopaticos en adultos, que podrían haberse detectado tambien en jovenes y niños.

\section{EL TRASTORNO DE CONDUCTA: UNA CATEGORIA HETEROGÉNEA}

El trastorno de conducta es una categoria diagnóstica la cual sirve para diagnosticar patrones de comportamiento antisocial que se mantienen en el tiempo y son extremos de acuerdo con el nivel evolutivo del niño, por lo cual entre el conflicto con la norma y los derechos o necesidades de los otros individuos. Se asume de manera general, que es una categoría heterogénea (QUAY, 1999), en la que se agrupan múltiples tipos de conducta, asi como diferentes trayectorias y etiologias.

Aunque existe consenso en que el trastorno engloba tipos heterogéneos, tradicionalmente no ha habido mucho acuerdo respecto a qué categorias, específicamente, se deben plantear dentro del mismo. Lynam (1997) señaló que los diferentes esfuerzos por clasificar estos, aun no tienen una amplia aceptación, por ello se han introducido diversos cambios a las versiones sucesivas del DSM.

Resumiendo, hay dos grandes tradiciones para clasificar los trastornos de la conducta. El primero parte de la investigación inductiva y multivariada, cuyo enfoque es agrupar entre si las diferentes conductas para conocer mas sobre ellas a través de técnicas como el análisis factorial. De esta manera se identifican los diferentes

RC: 91661

Disponível em: https://www.nucleodoconhecimento.com.br/psicologiaes/personalidad-psicopatica 
síndromes o patrones de comportamiento que aparecen conjuntamente en los sujetos.

Este tipo de estudio es realizado por Achenbach et al. (1989), el cual identifico dos grandes dimensiones: la primera propende a una conducta desafiante, negativista y de confrontación abierta; la segunda dimensión es de conductas no agresivas, encubiertas, que no presentan confrontación con otros individuos. La otra forma de investigar es a través de la aproximación clínica, se desarrolla basándose en los estudios de casos, para ello existen manuales de uso común para el diagnóstico de los trastornos mentales.

Anteriormente se planteó que en el DSM existen diferentes clasificaciones en relación a los trastornos de conducta. Por lo que, en el DSM-111 se contemplan cuatro tipos, resultantes de la combinación de dos criterios: socialización y agresión. El Infrasocializado Agresivo, se describe con características como dificultades para establecer vinculos afectivos con otros, poca empatía, egocentrismo, falta de remordimientos, conducta agresiva y arriesgada ... Aunque pocas veces se manifesta explicitamente (QUAY, 1987), esta categoria parecia recoger de un modo implícito las características del psicópata, y representaba un intento por extender el constructo psicopatia a individuos jóvenes.

A diferencia de los tipos infrasocializados, los socializados agruparian a niños cuya conducta antisocial se desarrolla en pandilla, como parte de una subcultura desviada en la que existen importantes vinculos grupales (por ejemplo, los aspectos interpersonales y afectivos) contribuyeron a que, en el DSM-111-R, se optara por subtipos basados en caracteres rnás evidentes. Asi, en lugar de girar en torno a lo afectivo-interpersonal, los nuevos subtipos se definen en función de si los actos antisociales son cometidos de manera grupal o de forma solitaria. Puesto que los antisociales solitarios presentan altos niveles de agresividad, los dos tipos retenidos en esta versión fueron el solitario Agresivo.

RC: 91661

Disponível em: https://www.nucleodoconhecimento.com.br/psicologiaes/personalidad-psicopatica 
Parecido a lo ocurrido con el TAP, son eliminadas las referencias a características personales, por lo que son difíciles de apresar de modo fiable, y se derivó a descripciones más conductuales, por lo cual se fue diluyendo el perfil psicopático recogido en el DSM-111.

Un giro aún mas grande se presenta en el DSM-IV, ya que el criterio que diferenciaba los subtipos de niños con trastornos de conducta es la edad de inicio: se clasifica en dos, uno es de incio infantil y el otro es de inicio adolescente. Los estudios longitudinales realizados al respecto habian puesto de relieve que los niños en los que la conducta problemática aparecía de manera temprana, presentaron una evolución persistente (FARRINGTON et al., 1990; PATTERSON; REID Y DISHION, 1992); ahora bien, los que iniciaron en la adolescencia presentaron un cuadro antisocial mas limitado a este período evolutivo, con menor riesgo de delincuencia adulta. Otros estudios, habia encontrado que ambos tipos tenian correlatos diferentes.

En los niños de inicio temprano, el trastomo de conducta aparecia frecuentemente asociado a disfunciones neuropsicologicas, a entornos familiares disfuncionales y desestructurados, con altas tasas de psicopatología en los padres y a dificultades en las relaciones con los iguales (MOFFITT, 1993). Cuando la conducta antisocial tiene su inicio adolescente, por el contrario, aparece más a menudo en jóvenes sin disfunción personal ni social previa y se vincula mas a grupos desviados.

El modelo desarrollado por Moffitt (1993) sobre la conducta antisocial juvenil, permite un desarrollo teórico a la distinción del DSM-IV: estableció que la conducta antisocial de inicio temprano es el resultado de la yuxtaposición entre un niño vulnerable y un entorno educativo adverso. Esta yuxtaposición origina una serie de transacciones que, desde los primeros años de vida, genera desadaptación en el niño; como un efecto de bola de nieve (ROMERO, 1998; ROMERO; LUENGO Y GÓMEZFRAGUELA, 2000), se limitan las oportunidades que permiten a este infante desarrollar una conducta que sea socialmente aceptada, por lo que el 
comportamiento criminal se va haciendo más crónico. Cuando la conducta antisocial inicia en la adolescencia, se considera una forma exagerada de experimentar un lapso madurativa que caracteriza a la adolescencia; la conducta antisocial serviría para reforzar la identidad del adolescente y ayudarle a experimentar un sentirniento de potencia y madurez.

De acuerdo con los resultados de la evidencia empírica, y de acuerdo con el modelo de Moffitt (1993), los antecedentes de la psicopatía adulta pudieran tener su origen en el inicio temprano, ya que es en estos niños donde se presentan las características de una disfunción neuropsicológica, relaciones interpersonales problemáticas y conducta antisocial crónica, todas estas asociadas a la psicopatia.

Se debe considerar los planteado por otros autores como McBurnett y Pfiffner (1998), los cuales indicaron que no todos los inicios tempranos terminan en desarrollo de una psicopatía. Por lo que hay que delimitar dentro de los trastornos de conducta de inicio temprano, aquellos niños que pertenecen a una categoría de mayor riesgo. Hasta ahora se presentan dos líneas de trabajo, por un lado la de Lynam y por el otro la de Frick, ambas 'presentan buenos argumentos y ambas analizan la medida en las que se puede identificar subgrupos de niños con características análogas a los psicópatas adultos.

Algunas de estas caracteristicas son:

Anormal/normal: Cotidianamente los individuos llaman a las conductas que le desagradan como "loco", "sádico", "paranoico", por mencionar algunos. De esta manera se excluye a esos individuos del resto de "nosotros", los llamados "normales". Sin embargo, esto es un estereotipo para que se olvide la influencia de la presión social o la fuerza de las situaciones cuando se presentan conductas anómalas, puesto que estas presiones pueden incitar que personas "normales" se comporten de manera desequilibrada. Lo anterior indica que es difícil diferenciar de una manera objetiva y radical la normalidad de la anormalidad. Sin embargo, hay criterios que permiten identificar a un individuo con trastorno de personalidad:

RC: 91661

Disponível em: https://www.nucleodoconhecimento.com.br/psicologiaes/personalidad-psicopatica 
- Se observa en esta persona poca estabilidad emocional o incapacidad de adaptación en condiciones de estrés. Por lo cual provoca situaciones críticas desde su percepción distorsionada de la realidad social.

- Es altamente inflexible, desde el punto de vista adaptativo.

- Las conductas patológicas se reputen como círculos viciosos, por lo tanto, provocan nuevos problemas y, poco a poco, se pierden las oportunidades de mejorar.

Entre las características mas comunes que presentan los individuos con alteraciones de personalidad las más frecuentes son:

- Surgen en todas las culturas y grupos sociales.

- Son pautas de conducta limitadas y muchas veces rígidas, por lo que impide que se desarrollen nuevos aprendizajes.

- Causan fragilidad emocional en situaciones de mucho estrés, porque los individuos pierden el control.

Trastornos de la personalidad, las cuales podemos observar en la tabla siguiente: 
Figura 1. Trastornos de la personalidad

\begin{tabular}{|c|c|}
\hline Trastomo & Definición \\
\hline $\begin{array}{l}\text { Personalidad } \\
\text { antisocial } \\
\text { (psicópata). }\end{array}$ & $\begin{array}{l}\text { Se trata de un individuo frío, duro, insensible, ambicioso y agresivo, con } \\
\text { baja tolerancia a la frustración. Le da igual el peligro o el castigo. Descuida } \\
\text { los derechos y el bienestar de los demás. Es rígido e inflexible, evita las } \\
\text { emociones tiernas por considerarlas signos de debilidad. }\end{array}$ \\
\hline $\begin{array}{l}\text { Personalidad } \\
\text { narcisista }\end{array}$ & $\begin{array}{l}\text { Es presuntuoso, mimado y explotador. Sobrevalora su importancia } \\
\text { personal. Dirige sus afectos hacia sí mismo más que hacia otros. Espera } \\
\text { que los demás reconozcan su valor único y personal. Quiere ser el centro } \\
\text { de atención y se comporta de forma exhibicionista. }\end{array}$ \\
\hline $\begin{array}{l}\text { Personalidad } \\
\text { dependiente }\end{array}$ & $\begin{array}{l}\text { Se caracteriza por la docilidad. Necesita que le ayuden y apoyen } \\
\text { constantemente. Tiene baja autoestima y sentimientos de inferioridad; } \\
\text { prefiere renunciar a la propia responsabilidad y dejar que los demás le } \\
\text { controlen y decidan por él. }\end{array}$ \\
\hline $\begin{array}{l}\text { Personalidad } \\
\text { histriónica }\end{array}$ & $\begin{array}{l}\text { Es superficial, frívolo, caprichoso y sin empatía. Su conducta es } \\
\text { excesivamente dramática, exagerada y afectivamente frágil, y sus } \\
\text { relaciones interpersonales se caracterizan por la inmadurez, la seducción y } \\
\text { la manipulación. }\end{array}$ \\
\hline $\begin{array}{l}\text { Personalidad } \\
\text { pasiva-agresiva. } \\
\text { Personalidad } \\
\text { negativista. }\end{array}$ & $\begin{array}{l}\text { Tendencia a decir siempre que no, no complacer a los demás, } \\
\text { malhumorado, pesimista y quejica. Suele estar descontento y desmoralizar } \\
\text { a los demás. }\end{array}$ \\
\hline $\begin{array}{l}\text { Personalidad } \\
\text { obsesivo- } \\
\text { compulsiva. }\end{array}$ & $\begin{array}{l}\text { Tiene tendencia a construir su mundo en términos de reglas y normas, } \\
\text { esquemas y jerarquías. Se relaciona con los demás según su rango y } \\
\text { estatus. Los valores convencionales son las reglas con las que vive. Es } \\
\text { afectivamente reprimido, solemne y serio. No expresa su afecto por miedo } \\
\text { a experimentar emociones incontrolables. }\end{array}$ \\
\hline $\begin{array}{l}\text { Personalidad } \\
\text { esquizoide. }\end{array}$ & $\begin{array}{l}\text { Consiste en la incapacidad para percibir el humor o las necesidades de los } \\
\text { demás. La persona esquizoide es insensible y poco comunicativa. Es } \\
\text { impreciso sobre sus metas, indeciso en sus acciones, permanece absorto en } \\
\text { sí mismo y está aislado socialmente. Trabaja calladamente y rara vez atrae } \\
\text { la atención de quienes están en contacto con él. }\end{array}$ \\
\hline $\begin{array}{l}\text { Personalidad } \\
\text { paranoide. }\end{array}$ & $\begin{array}{l}\text { Es la tendencia a estar siempre en guardia y a desconfiar de los demás; } \\
\text { rechaza las relaciones personales intimas, en las que exista una pérdida de } \\
\text { poder, de independencia y autocontrol. La persona se vuelve suspicaz, } \\
\text { resentida y hostil. }\end{array}$ \\
\hline
\end{tabular}

Fuente: McBurnett y Pfiffner (1998)

\section{LA HIPERACTIVIDAD EN EL PSICÓPATA INCIPIENTE}

En los últimos años, diversos autores han coincido en proponer que la combinación del trastorno de conducta con el déficit de atención con hiperactividad (TDAH) 
representan un antecedente de la psicopatía adulta (KLINTENERG, 1996; MCBURNETT Y PFIFFNER, 1998). Posteriormente, este estudio fue desarrollado por Lynam.

Al respecto, en su artículo, Lynam (1996) analiza de forma detallada, las diversas fuentes de evidencia que apoyan su planteamiento. En este análisis demuestra que en la concurrencia de hiperactividad y trastorno de conducta, se puede identificar a lo que se denomina el psicópata incipiente. En primer lugar, diversos estudios longitudinales muestran que los niños en los que ocurren sintomas de hiperactividad y problemas de conducta tienen una conducta antisocial más severa en la adultez (por ejemplo, mas contactos policiales, más versatilidad, agresividad y autorobos) (LOEBER; BRINTHAUPT Y GREEN, 1990). Estas investigaciones indican que el pronóstico de los niños, en lo que a actividad antisocial se refiere, es peor que en aquellos que solo presentan uno de estos, o trastorno de conducta o hiperactividad

Otra línea de investigación hace alusión a los estudios de familias. En estos trabajos la finalidad es investigar si los parientes adultos de los niños con hiperactividad y problemas de conducta, también presentan altas tasas de psicopatía o TAP. Al respecto, Lahey et al. (1987) examinó las historias psiquiátricas de las familias en c cuatro grupos de niños, separados de la siguiente manera: (a) niños con hiperactividad; (b) niños con problemas de conducta; (c) niños con ambos trastornos y; (d) niños sin ningún trastorno. Los padres de los niños que presentaban ambos trastornos presentaban un historial de conducta antisocial más severa que los los padres de los otros grupos. Se halló que la conducta antisocial de los padres no tenía relación en absoluto con la hiperactividad, excepto en aquellos casos de concurrencia con trastorno de conducta.

Los estudios demuestran que la conducta antisocial infantil esta asociada a indicadores de alto riesgo que pueden predecir una conducta problemática en la adultez (LOEBER Y DISHION, 1983): una edad de inicio más temprana esta asociado a mayores frecuencias de severidad y variedad en la conducta antisocial

RC: 91661

Disponível em: https://www.nucleodoconhecimento.com.br/psicologiaes/personalidad-psicopatica 
manifestada en diferentes situaciones en la casa o en la escuela. Una herramienta eficaz es el bootstrapping, la cual analiza si los niños con hiperactividad mas problemas de conducta presentan en mayor medida indicadores de riesgo psicopático.

Estas líneas de investigación ligan la combinación de hiperactividad más problemas de conducta con un comportamiento antisocial severo en la adultez, pero no se ha asociado directamente al concepto de psicopatía, lo cual era entendido tradicionalmente. Po lo que la evidencia descrita parecería avalar la idea de que este subgrupo de niños pudiera presentar mayor riesgo de TAP, pero no necesariamente del constructo clásico de psicopatia.

En tal sentido, Lynam (1996) también ha planteado en sus investigaciones que la relación entre este subgrupo de niños y la psicopatía es muy débil. Sin embargo, este investigador revisó los estudios que sugerían que los niños hiperactivos se comportan de un modo similar a los psicópatas adultos. Estos estudios encontraron que los niños presentaban déficits en el aprendizaje de evitación pasiva, además de tener dificultades para dar su respuesta en dependencia de las contingencias ambientales; parecido a los adultos, insisten en una respuesta a pesar de que las probabilidades de ser castigados vayan aumentando (MILICH et al., 1994).

Otras trabajos demuestran que los niños hiperactivos (o una parte considerable de ellos), presentaron indicadores de un bajo arousal cortical, con una pobre ejecución de tareas neuropsicológicas relacionadas con las funciones ejecutivas frontales. Lyman sostiene la hipótesis (aunque solo hay contados casos) que el subgrupo de niños con hiperactividad y trastorno de conducta presentan características similares al psicópata adulto. Otros trabajos de Lynam (1998) presentan datos consistentes con esta hipótesis.

Este autor (LYNAM, 1996) también realizó hipótesis sobre la naturaleza de las relaciones que se presentan entre hiperactividad, trastorno de conducta y psicopatía. Plantea varias posibilidades, entre ellas que la hiperactividad es una de los muchos

RC: 91661

Disponível em: https://www.nucleodoconhecimento.com.br/psicologiaes/personalidad-psicopatica 
factores de riesgo del trastorno de conducta y éste conduce a la criminalidad adulta; por lo que la hiperactividad conduce a conductas desafiantes tempranas y éstas son las que llevan a los trastornos de conducta, que acarrean implicaciones diferentes en la prevención y tratamiento.

Insiste Lynam en prestar una atención especial a su hipótesis que es la concurrencia de hiperactividad mas trastorno de conducta, ambas representan un subgrupo especial del trastorno de conducta, ya que representa una psicopatía incipiente, cuyo mecanismo tiene su raíz en el déficit de inhibición, un ejemplo de esto es la dificultad en modular las respuestas asociadas al sistema serotonérgico. Estas inhibiciones son las responsables de los tres tipo de síntomas del TDAH: (a) la inquietud motora y la hiperactividad; (b) la falta de atención cuando el niño persigue una recompensa y; (c) las conductas impulsivas.

Esta capacidad de inhibición dan paso al choque con las normas, generando conductas desafiantes tempranas, cuyo espiral de efectos adversos conduce al trastorno de conducta. Finalmente, ese mismo déficit de inhibición dara lugar a las características que presentan los psicópatas adultos (ALUJA, 1991).

Lo planteado anteriormente, y teniendo en cuenta que el subgrupo de hiperactividad + trastorno de conducta será etiológicamente diferente, se requerirá de una estrategia de tratamiento especial. Una estrategia es el uso de fármacos de actuación selectiva sobre el sistema serotonérgico, a esta se le suma la aplicación de estrategias cognitivas con la finalidad de ayudarlos a reflexionar, pensar y examinar el ambiente donde se desarrolla, todas estas son vias adecuadas.

La intervención temprana sobre este subgrupo llevaria a la prevención de la psicopatia adulta. En resumen, de acuerdo con Lynam, el constructo de psicopatías infanto-juveniles se localiza en las taxonomias de uso común, en el subgrupo de niños presentan trastornos de conducta e hiperactividad. Otros autores, sin embargo, consideran que ese subgrupo de niños es aún una categoria demasiado 
amplia y que es necesario realizar un enfoque más especifico para identificar a los niños con rasgos psicopáticos.

En esta linea desarrolla su trabajo Frick, con cifras que abarcan entre el $65 \%$ y $90 \%$ de muestras clínicas de niños con trastorno de conducta, detectando que la comorbilidad entre el TDAH y el trastorno de conducta es alta, por ello se necesita considerar cuál es el punto donde los niños afectados por ambos trastornos pueden presentar la psicopatía como desorden que, considerando las cifras estimadas en adultos, se comporta de manera mucho más frecuente.

Adicionalmente, Frick estima que en esta categoria propuesta por Lynam no están bien reflejadas ciertas características críticas del constructo psicopatía, por ejemplo. la insensibilidad emocional, la falta de remordimientos o la empatía. Cuando se combina un deficiente control de impulsos (TDAH) con una conducta antisocial (trastorno de conducta), los resultados se asemejan con el perfil general de los adultos antisociales, donde solo un subgrupo podria considerarse psicópatas.

En su análisis de la psicopatia infantil, Frick seguira una estrategia diferente a la de Lynam. Lynam parte de categorías diagnósticas bien establecidas y, en ellas, intenta identificar cuál se aproxima mis a la psicopatia. Frick, sin embargo, parte directamente del concepto de psicopatía en los adultos y desde allí, intenta comprobar si esos rasgos centrales de dicho concepto permiten caracterizar un grupo particular de niños.

Es necesario indicar que los trabajos de Frick asumen de manera explicita el modelo de Hare. En 1994, el equipo de colaboradores de Frick desarrolló una escala de calificación inspirada en el PCL-R: El Psychopathy Screening Device (PSD) (FRICK et al., 1994). Estos autores crearon 20 item análogos a los del PCL-R, que se presentan como una escala de calificación de tres puntos: O (absolutamente falso), 1 (a veces verdadero) y 2 (absolutamente verdadero). La escala debe ser complementada bien sea por los padres o por los profesores, aunque también fue creada una versión que puede ser llenada por el mismo adolescente.

RC: 91661

Disponível em: https://www.nucleodoconhecimento.com.br/psicologiaes/personalidad-psicopatica 
La primera vez que se realizó un análisis factorial de esta escala (FRICK et al., 1994), basado en una muestra clínica de 92 niños con el uso de puntuaciones combinadas de padres y profesores, reveló una estructura compuesta por dos factores.

El primer factor estuvo compuesto por 10 items que se relacionaban con un deficiente control de impulsos, falta de responsabilidad y conductas problemáticas. Por la anterior este factor se denominó Impulsividad/Problemas de Conducta (VPC).

El segundo factor agrupa 6 items referidos a insensibilidad emocional (por ejemplo, falta de sentimientos de culpa, emociones superficiales, falta de empatia) y fue denominado (Dureza ínsensibilidad emocional). Los anteriores dos factores indicados guardan similitud con los dos factores indicados en la literatura sobre el PCL en adultos, Aunque, como indica Frick (1998), no pueden consigo. Las etiquetas utilizadas en inglés han sido Impulsivify/Conduct Problerns (IICP) y Callous/Unemotional (CU), respectivamente.

Una de las diferencias más notables es que los items referidos a narcisismo, piensa que es más importantes que los demás forman parte del factor impulsivo/antisocial, rnientras que en los adultos, estos contenidos se unen en la dimensión que se a denominado de desapego e insensibilidad emocional.

Análogamente a los factores del PCL, la correlación entre I/CP y DI esto en torno. Ya en este primer trabajo, se encontró que los dos factores tienen correlaciones diferentes con otras variables. El factor $\mathrm{r} / \mathrm{cp}$ presenta correlaciones altas con medidas de problemas de conducta, entre ellas se encuentran las definiciones de trastorno negativista desafiante y del trastorno de conducta del DSM-III-R y, en líneas generales, el factor I/CP capta un constructo que se asemeja a las definiciones tradicionales de problemas de conducta. Por lo tanto, el factor DI, puede ser asociado, por lo menos a estas categorías. Adicionalmente, cuando se realza el análisis de las interacciones significativas entre las variables develó, en los niños con problemas de conducta, que se puede definir un subgrupo, alto en DI, que

RC: 91661

Disponível em: https://www.nucleodoconhecimento.com.br/psicologiaes/personalidad-psicopatica 
tendría características diferenciales; como ejemplo de lo anterior se puede mencionar los niveles intelectuales más altos o la frecuencia de arrestos que tiene la familia.

Los investigadores Christian et al. (1996) identificaron un subtipo de niños problemáticos, estos presentaban puntaciones altas de ID y algunos rasgos particulares. Su trabajo realizado sistemáticamente en una muestra clínica de 120 niños que tenían edades comprendidas entre 6 y 13 años, a través de un analisis clúster, se pudieron definir dos grupos con conductas problemáticas.

Ambos puntuaban alto en la dimensión Vpc, por lo que se les había realizado un diagnóstico de trastorno negativista desafiante, el cual es un trastorno de conducta que había comenzado temprano en su problemática conductual. En estos grupo se identifico uno al que se denominó compulsivo, el cual puntuaba bajo en DI, mientras que el otro, se llamó psicopático y puntuaba alto en esta dimensión.

Un avance en esta investigación consistió en comprobar que el grupo psicopático mostraba mayor variedad y tasas altas en conductas antisociales, y a pesar que no alcanzó la significación estadistica, el grupo psicopático tendia a mostrar mas contactos con la policia y una mayor frecuencia de TAP en los padres $(p<.07$ y $p<$ .09 , en correspondencia).

En así que la dimensión DI delimita dos grupos en los niños que presentaban problemas de conducta; los de alto índice DI se asocian con los indicadores que proyectan un pronóstico peor ya que es más afín con la psicopatía adulta. Esta diferenciación en útil ya que se probado en muestras aplicadas a delincuentes institucionalizados. Mas reciente, Captu; Frick y Brodsky (1999) realizaron un estudio en adolescentes con edades comprendidas entre 13 y 18 años tomando una de 69 jóvenes, empleó la versión autoinformada del PSD; entre los hallazgos se encuentra que la dimensión DI diferenciaba a los delincuentes sexuales violentos de otros delincuentes institucionalizados, ya que los primeros presentan mayores puntuaciones de DI.

RC: 91661

Disponível em: https://www.nucleodoconhecimento.com.br/psicologiaes/personalidad-psicopatica 
En este mismo orden de ideas, Silverthon; Frick y Reynolds (1998) realizaron un estudio donde se comprobó que los delincuentes que tuvieron un inicio temprano en la conducta antisocial obtenían alcanzaron puntuaciones mas altas en DI, al compararlos con aquellos delincuentes que presentaron un inicio tardío. Otro estudio realizado por Kruh; Frick y Clements (1999), en una muestra de 100 sujetos que tenían una edad promedio de 18,36 años y estaban recluidos en una prisión de adultos a pesar que habían sido recluidos por crimenes cometidos como delincuentes juveniles, donde todos los participantes presentaban un amplio historial delictivo con altas tasas de violencia. Llegó a la conclusión que las puntuaciones en el PSD se correlacionan con las tasas de delitos y versatilidad de los mismos, además con la diversidad de actos violentos que cometieron durante el encarcelamiento.

Recientemente, algunos estudios profundizan en los correlatos psicosociales, personales y conductuales de la conducta tanto psicopática como no psicopática, con el fin de perfilar posibles mecanismos etiológicos. Como ejemplo de esto, se han conseguido prácticas de socialización parental (las cuales son consistentes con los correlatos de la conducta antisocial mas replicados; Romero et al., 2000) pero no se relacionan con las conductas problemáticas de los niños que presentaron altos DI (WOOTON et al., 1995).

Independientemente de la calidad en los estilos educativos, estos niños de características más psicopáticas tienen altos niveles de problemas de conducta. Ahora bien, aquellos niños con bajo DI, si presentan relación entre las practicas familiares y la gravedad de la conducta. Existen otros trabajaos que relacionan las dimensiones del PSD con la sensibilidad a las claves de castigo. En 1994, el equipo liderado por Frick (O’BRIEN; FRICK Y LYMAN, 1994) realizó una investigación con el uso de un paradigma similar al de Newman, encontrando que el patrón de perseveración identificado en estudios realizados a adultos, parece consistente con los de niños que presentan trastornos de conducta, pero sin los altos niveles de ansiedad. Desde la creación del PSD y del desarrollo de modelo de psicopatía, se 
intenta examinar si ese resultado puede deberse a que los niños que tienen problemas pero que no son ansiosos, se aproximan a la categoría psicopática. Por otro lado, O’Brien y Frick (1995) parten de la teoría que la perseveración se produce en niños no ansiosos que puntúan alto en $\mathrm{DI}$, presente $\mathrm{o}$ no problemas conductuales.

En este sentido, la dificultad para dar respuesta al castigo en una tarea tipo Newman, se relaciona con aquellos rasgos psicopáticos de dureza/insensibilidad, y solo de manera indirecta con los problemas de conducta. Contradiciendo a la propuesta de Lynam, según todo el grupo problema mas conducta sería un grupo psicopático, Bany et al. (2000) encontró que dentro de los niños con TDHA y problemas de conducta solo cuando el DI es alto aparece este estilo de respuesta.

Es importante en este estudio analizar sistemáticamente, la relación que existe entre la ansiedad y la psicopatía en niños. En tal sentido, Frick et al. (1999), señalan que la literatura acerca de ansiedad y conducta antisocial es un poco confusa. Algunos estudios teóricos indican la ausencia des ansiedad como una característica que indica predisposición a la psicopatía, a la conducta antisocial o a ambas. Pero la investigación demostró que en individuas antisociales es frecuente observar altos niveles de ansiedad. Para estos autores, resolver esta paradoja requiere, por un lado, la diferenciación entre los dos componentes de la psicopatía; y, por otro, introducir la distinción propuesta por diversos investigadores, entre la ansiedad como afecto negativo y la (falta de miedo), entendida como sensibilidad a las señales de peligro.

Frick et al. (1999) encuentran, en una muestra clínica de 143 niños, que los componentes de la psicopatia se relacionan diferencialmente con ambos tipos de ansiedad. Utilizando correlaciones parciales, se encuentra que la ansiedad como afecto negativo, evaluada a través de sintomas de trastornos de ansiedad del DSM111-R y tomando en cuenta la lista de chequeo de Achenbach (1991) de la escala de Ansiedad/Depresión (1991), correlaciona positivamente con medidas de

RC: 91661

Disponível em: https://www.nucleodoconhecimento.com.br/psicologiaes/personalidad-psicopatica 
problemas de conducta y negativarnente con la dimensión DI. Se destaca que la falta de miedo, evaluada a través de la búsqueda de emociones y aventuras indicada en la Escala de Búsqueda de Sensaciones para Niños por Russo et al. (1993), no se correlaciona significativarnente con la dimensión VCP y si se relaciona (aunque débilmente), en sentido positivo, con DI. La (falta de miedo) parece entonces mis vinculada con las características centrales de la psicopatía desempeñando un papel importante en el estilo motivacional que subyace en este trastorno.

En tal sentido, la ansiedad se convierte en un factor negativo indicador del malestar que hubiera generado la conducta del niño, relacionándose, por tanto, con la actividad antisocial; en los niños con alta $\mathrm{Di}$, sin embargo, parece producirse un menor malestar, lo cual podria contribuir a la gravedad de su conducta.

Encajando los datos de esta linea de investigación, Frick propone un modelo etiológico según el cual los problemas de conducta de inicio temprano podrán estar respondiendo a diversas vías causales (FRICK, 1998, FRICK; BARRY Y BODIN, 2000; FRICK Y ELLIS, 1999). Concretamente, de acuerdo con lo expuesto, podriamos distinguir dos grupos; es importante destacar que en ambos los problemas de control de impulsos son centrales, de la misma manera se presenta una alta morbilidad con el TDHA. Sin embargo, en el grupo que no tenia características de DI, la etiología es muy heterogénea: por mencionar un ejemplo, en algunos sujetos de investigación fue un factor crucial radicar en ambientes de crianza problemáticos, mientras que en otros fue la baja inteligencia la que dio lugar a las dificultades. En cambio, el grupo psicopático, con un alto DI, respondió etimológicamente mas homogéneo.

Es por ello que Frick apela a los deficits de inhibición conductual, en la misma línea de estudio que Lynam. Los déficits senan reflejo de un débil BIS, y se manifestarian en la falta de miedo en tareas que exigen modulación de la conducta en respuesta a señales de castigo. Actualmente, dentro de esta corriente de investigación, se 
desarrollan diversas vias para realizar los estudios. Se pueden mencionar el modelo de chicas propuesto por Silverthon y Frick (1999). A pesar que Frick se distingue de Moffitt (1993) por su distinción entre los problemas conductuales de inicio temprano y los de inicio tardio, se ha encontrado que los sujetos de investigación femeninos inician en la adolescencia pero presentan características similares a los sujetos de investigación masculinos de inicio temprano; Este análisis de rasgos DI realizado en los sujetos de investigación femeninos permitirá identificar hasta que punto es aplicable el modelo de Frick en los sujetos de investigación femeninos de inicio demorado.

También se estudio la validación de PSD con otros trabajos en muestras realizadas a la población general (FRICK; BODIN Y BARRY, 2000). Por ahora, los resultados obtenidos con una muestra de 1136 niños, aplicando el PSD a través de padres y profesores, revelan una estructura de tres factores.

El grupo de Frick ha investigado en adultos jdvenes la relación entre síntomas de somatización y las dos dimensiones de la psicopatia (WILSON; FRICK Y CLEMENTS, 1999). Los resultados son análogos a los encontrados con las medidas de ansiedad como afecto negativo. Un modelo etiológico que guarda su desgaja en dos: un factor que contiene items de narcisismo y un factor que contiene items de impulsividad.

En España, en un estudio muy preliminar sobre problemas de conducta en niños, se recogieron datos en una muestra de 165 niños de la población general, de edades comprendidas entre 10s 6 y 12 años de edad (un grupo comprendido por 95 varones y 70 mujeres). El análisis factorial del PSD realizado por los profesores caracterizó la estructura de tres factores que lograron valores superiores a 1 y explican una varianza de $65,39 \%$. Estos hallazgos encontrados en los factores se ajustan a los obtenidos por Frick en la muestra de la población general. Un primer factor es definido por items de narcisismo, dominancia y manipulación (alpha $=.91$ ); un segundo factor recoge los aspectos de impulsividad y actividades arriesgadas (alpha

RC: 91661

Disponível em: https://www.nucleodoconhecimento.com.br/psicologiaes/personalidad-psicopatica 
$=.92)$; un tercer factor incluye los aspectos de insensibilidad emocional y falta de empatia $($ alpha $=.70)$.

Así, la interrelación de estos factores, siendo ( $p<0,001)$, corresponde a 0,60 entre Narcisismo e Impulsividad; 0,35 entre Narcisismo y Dureza; más 0,36 entre Impulsividad y Dureza.

Entre las caracteristicas mas destacadas se puede mencionar, en los topicos relacionados al Narcisismo, Impulsividad, Insensibilidad que los niños son:

- Fanfarrones respecto a sus propios logros. $98 \%$

- Piensa que es mis importante que los demás. 91\%

- Manipula a otras personas. $76 \%$

- Le toma el pelo a otras personas. $66 \%$

- Sus emociones parecen superficiales y poco auténticas. $62 \%$

- Se pone furioso cuando se le corrige. $54 \%$

- Puede parecer amable a veces, pero de una forma poco sincera. $51 \%$

- No planifica. $83 \%$

- Se implica en actividades peligrosas o arriesgadas. $77 \%$

- Se implica en actividades ilegales. $73 \%$

- Se aburre fácilmente. $72 \%$

- Se preocupa por el rendimiento escolar. $42 \%$

- Actúa sin pensar en las consecuencias. 67\%

RC: 91661

Disponível em: https://www.nucleodoconhecimento.com.br/psicologiaes/personalidad-psicopatica 
- Cumple sus promesas. $58 \%$

- Miente fácilmente. $66 \%$

- Culpa a otros. $49 \%$

- No muestra emociones o sentimientos. $75 \%$

- Siempre tiene los mismos amigos $61 \%$

- Se preocupa por los sentimientos de los demás $44 \%$

- Valores propios $56 \%$

Estas podrían entonces ser las caracteristicas más evidentes de niños con psicopatía incipiente.

Frick et al. (2000) basado en Hare (1997) ha analizado cómo se relacionan estos factores (Narcisismo, impulsividad e insensibilidad) están relacionados con los criterios del DSM-IV con respecto a los problemas de conducta.

Así, en definitiva, su investigación amplió el modelo de Hare al sugerir que las características de insensibilidad permiten la diferenciación de dos grupos de niños con conductas problemáticas iniciales, proponiendo el desarrollo de otras características relacionales en el contexto familiar, por ejemplo, entre padres hijo, y sugieren el desarrollo de habilidades o pasatiempos en estos niños como forma de evitar comportamientos antisociales.

\section{PSICOPATÍA INFANTIL VISTO DESDE LA PERSPECTIVA DE ROBERT HARE}

Aunque la producción científica sobre la psicopatía infantil y adolescente es escasa, los estudios han demostrado que el trastorno se inicia en la infancia. Algunas investigaciones incluso han identificado que la presencia de este trastorno en la infancia o la adolescencia puede predecir conductas delictivas en la etapa adulta.

RC: 91661

Disponível em: https://www.nucleodoconhecimento.com.br/psicologiaes/personalidad-psicopatica 
De esta forma, Cleckley definió, en 1976, la personalidad psicopática en un conjunto de características clave, siendo estas:

- Estas personas muestran un encanto superficial e inteligencia elevada.

- No presentan delirios ni otros síntomas de pensamiento irracional.

- Ausencia de nerviosismo y de otros síntomas neuróticos.

- Falta de sinceridad.

- Falta de remordimientos y vergüenza.

- Conducta antisocial sin un motivo adecuado para ello.

- Incapacidad de aprender de las experiencias.

- Egocentrismo patológico e incapacidad de amar.

- Afectividad limitada.

- Falta de intuición.

- Indiferencia hacia las relaciones personales.

- Conducta sorprendente y poco deseable.

- El suicidio es algo infrecuente.

- Trivialidad sexual.

- Incapacidad para seguir un plan de vida coherente.

Robert Hare, por su parte, afirma que los psicópatas son depredadores de su propia especie, que se distinguen por sus aspectos afectivos, interpersonales y conductuales:

- Aspectos afectivos: sus emociones son superficiales y cambian rápidamente; carecen de empatía y no logran mantener relaciones a largo plazo con otras personas.

- Aspectos interpersonales: suelen ser arrogantes, dominantes, egocéntricos, manipuladores y enérgicos.

- Aspectos conductuales: son irresponsables e impulsivos, siempre buscan sensaciones nuevas y fuertes, a menudo rompen las normas sociales y tienden a tener un estilo de vida social inestable. 
Además, se describen otras características, tales como:

- Ausencia de remordimientos y sentimiento de culpa ante los comportamientos que pueden dañar a otras personas.

- Insensibilidad emocional.

- Los niños suelen ser más difíciles y traviesos, constantemente intentan desafiar las normas y a las personas de autoridad.

- Utilizan la mentira de forma patológica.

- Comportamiento agresivo, que causa daño físico o amenaza a personas o animales y además muestra crueldad en estos comportamientos. Aparecen conductas destructivas y/o prende fuego de objetos.

- Con frecuencia están aislados socialmente, no se involucran en actividades ni relaciones interpersonales.

\section{DIAGNÓSTICO DE LA PSICOPATÍA INFANTIL}

El logro de un diagnóstico adecuado es de suma importancia para los niños o adolescentes considerados normales para diferenciarse de los que presentan este tipo de trastorno.

Seagrave y Grisso, así como otros autores, informan que muchas de estas características psicopáticas son inherentes a la fase adolescente del desarrollo humano. Sin embargo, aunque están de acuerdo con esta afirmación, otros autores consideran que la manifestación anormal de estas características en la infancia o la adolescencia son síntomas de psicopatía.

Cuadro $N^{\circ}$ 1: Diagnostico de Psicopatía en Niños y Adolesentes

\section{Diagnostico}

Causas Existen numerosos estudios sobre las causas que llevan a desarrollar este trastorno psiquiátrico. Las investigaciones en este

RC: 91661

Disponível em: https://www.nucleodoconhecimento.com.br/psicologiaes/personalidad-psicopatica 
Factores

Genéticos

Factores

biológicos

Factores

psicológicos

Tratamiento campo continúan porque no se ha encontrado un determinante claro para su desarrollo. Más bien parece el resultado de la influencia de varios factores.

Se han realizado numerosas investigaciones con familias, con gemelos, o niños adoptados. Los resultados demuestran que los genes pueden ser responsables de que algunos individuos sean vulnerables a desarrollar este tipo de trastorno.

Pero ningún gen único es el responsable del trastorno. Se trata de múltiples genes que se combinan para generar esa vulnerabilidad. Y por otro lado, el riesgo de padecer el trastorno podría variar en función de la cantidad de genes que comparte un individuo con alguien que padece la enfermedad.

Algunos estudios indican que el daño o disfunción cerebrales pueden ser influyentes a la hora de desarrollar el trastorno. Por otro lado, parece existir una falta de conexión entre la amígdala (encargada de regular las emociones) y la corteza prefrontal en estos sujetos. También se han realizado investigaciones en torno a la influencia que pueden tener neurotransmisores como la dopamina o serotonina.

La teoría predominante en este campo es el denominado modelo de vulnerabilidad-estrés. Tiene como supuesto básico que para que se llegue a desarrollar el trastorno es necesario la existencia de una vulnerabilidad, que puede ser activada por diversos estresores que precipitan la aparición del trastorno.

En cuanto al tratamiento de este trastorno aún no se ha demostrado que exista un tipo de intervención que sea exitosa con estos individuos. Los estudios en este contexto son además pesimistas y

RC: 91661

Disponível em: https://www.nucleodoconhecimento.com.br/psicologia- 
algunos autores como Harris y Rice incluso concluyen que en algunos casos el tratamiento no sólo no es efectivo sino que además puede ser contraproducente.

Los principales problemas a la hora de realizar una intervención son por un lado las limitaciones que presentan los estudios que se han realizado al respecto, y por otro, las propias características de estos individuos que hacen el tratamiento poco efectivo.

Entre estas características destacan la imposibilidad de crear un vínculo entre el terapeuta y el paciente; no sienten la necesidad de cambiar, no existe una comunicación sincera e imposibilitan el trabajo emocional.

En el año 2000 Lösel ha resumido una serie de principios que deben guiar la intervención con estos sujetos teniendo en cuenta el estudio de los tratamientos aplicados hasta ese momento que demuestran ser los más eficaces. Según concluye, los programas de tratamiento deberían contar con estos fundamentos:

-Deben estar basados en los estudios sobre la causa de la psicopatía a nivel psicológico y biológico.

-Realizar una evaluación profunda del individuo para que derive en un diagnóstico preciso y no confundir el comportamiento habitual de un adolescente con rasgos patológicos.

-Seguir un tratamiento intensivo y prolongado.

-Realizar el tratamiento en instituciones estructuras y especializadas en estos casos para evitar la posible manipulación del psicópata. 
-Crear un ambiente positivo en la institución y mantenerlo frente a las conductas hostiles de los sujetos tratados.

-Dirigir parte del tratamiento en hacerles entender que sus conductas antisociales son perjudiciales principalmente para ellos, ya que en principio perjudicar a los demás no tiene ningún efecto negativo para ellos.

-Los programas de tratamiento con una orientación multimodal y cognitivo-conductual han resultado ser los más exitosos en este ámbito.

-Asegurarse de que el programa de tratamiento se cumple íntegramente.

-Seleccionar, formar y supervisar de forma minuciosa a los profesionales que van a intervenir en el tratamiento.

-Reforzar los factores de protección naturales, como unos padres firmes y consecuentes que fomenten el desarrollo de aptitudes prosociales.

-Realizar un seguimiento controlado una vez que el sujeto termina el tratamiento y prevención de recaídas.

-Aunque a día de hoy no exista un programa que se haya mostrado eficaz en el tratamiento de los niños, adolescentes y adultos con esta patología, siguen realizándose estudios e investigaciones encaminadas a dar con él.

Kochanska en 1997 ya resaltó la importancia de evaluar el temperamento de los niños porque aquellos con características de 
personalidad poco temerosas van a tener dificultades para desarrollar emociones como la culpa o la empatía.

Así mismo queda constancia de que las intervenciones con los niños y adolescentes tienen que ir principalmente encaminadas a controlar los impulsos antisociales con un tratamiento estricto y ordenado para el cumplimiento de las normas y hábitos.

Pero en definitiva, a día de hoy no se ha concluido que tipo de intervención es la adecuada para una persona con estas características. Es necesario saber más acerca de las causas y los procesos implicados en su desarrollo para poder aportar un tratamiento conjunto desde la farmacología y la psicología.

Fuente: Adaptado de Hare (1997)

\section{MARCO METODOLÓGICO}

La presente investigación esta orientada hacia un tipo de investigación documental, con diseño bibliográfico la cual consiste en la revisión de documentos y materiales en forma sistemática, rigurosa y profunda que permite llegar al análisis de diferentes fenómenos.

Tamayo (2012) lo define como "aquel que utiliza datos secundarios, es decir, aquellos obtenidos por otros y se llegan elaborados y procesados de acuerdo con los fines de quienes inicialmente lo elaboran y lo manejan." (p.70)

\section{TIPO DE INVESTIGACIÓN}

En atención al enfoque epistemológico seleccionado, la investigación está basada en el tipo documental. Según lo establece la Universidad Metropolitana (UNIMET, 2002).

RC: 91661

Disponível em: https://www.nucleodoconhecimento.com.br/psicologiaes/personalidad-psicopatica 
La investigación analítica tiene como objetivo analizar un evento y comprenderlo en término de sus aspectos menos evidentes, así mismo trata de entender las situaciones en términos de sus componentes e intenta descubrir los elementos que componen una situación y luego hacer una síntesis de lo analizado. (p. 24).

Según la UNIMET (2002) el análisis se convierte en una herramienta para descomponer el fenómeno. Específicamente se hizo un análisis del contenido de los documentos seleccionados, el cual busca el significado y comprensión de las expresiones a través de la lectura analítica - crítica durante el proceso de revisión del material escrito.

El proceso analítico permite descomponer la realidad hasta sus mínimas unidades de sentido, con el propósito de realizar una elaboración conceptual del mismo. Esta elaboración, de una u otra forma, incorpora en su enunciación conceptual los casos que se quieren observar, las características a observar, el porqué de la investigación y los contextos en los cuales interesa estudiar el fenómeno. Sin embargo, llegar a esa enunciación implica un proceso de búsqueda y de reflexión por medio de una revisión bibliográfica que posibilite discutir lo que otros investigadores han planteado sobre el objeto de interés.

Hacer esta reflexión implica, entonces, tener una apertura que permita discutir diversos enfoques y evaluar cuáles de ellos son los más adecuados para abordar el objeto de estudio, ello posibilitó la construcción de un marco referencial que contiene el abordaje teórico, conceptual y metodológico para enfrentar el objeto de estudio como lo expresa Díaz Barriga y Henríquez, (2003). Esto debería llevar naturalmente al analisis del objeto, que permite tomar conciencia de lo que se quiere saber sobre el fenómeno en estudio (objetivo general y específicos) y las orientaciones generales respecto a lo que se debe buscar y se puede encontrar.

En esa medida, esta construcción vincula el análisis con la síntesis, donde a partir del procedimiento técnico de codificación, los elementos constitutivos del objeto 
(información) se transforman en datos que incorporan los constructos rectores en sí mismos.

Vale la pena resaltar que la codificación puede hacerse de forma rígida, donde se sustente los procesos de codificación a fin de recomponer lo desarticulado para llegar a una totalidad que exprese el objeto de estudio. En este sentido los datos fueron sometidos a diversos "tratamientos" que nos permitieron de alguna manera, reordenarlos, resumirlos y relacionarlos. Se trató de descomponer y recomponer el discurso al estilo de Van Dick.

Al respecto del tipo de investigación documental se puede destacar lo señalado por Bravo y otros (2002), al considerarla como:

La estrategia para la observación, reflexión y análisis de un fenómeno de la realidad a través de la indagación exhaustiva, sistemática y rigurosa de diferentes tipos de documentos, que directa o indirectamente aporte información acerca de la realidad estudiada. (p. 175)

Con base en lo expresado por autores anteriores, se sabe que la investigación documental investiga, interpreta y presenta datos e información sobre un tema determinado, a través de un método analítico, con el fin de obtener resultados relevantes para el desarrollo de un estudio científico.

En este sentido, la Investigación Documental se puede caracterizar según Bravo y otros (2002), de la siguiente manera:

Se caracteriza por la utilización de documentos; recolecta, selecciona, analiza y presenta resultados coherentes.

- Utiliza los procedimientos lógicos y mentales de toda investigación; análisis, síntesis, deducción, inducción,

- Realiza un proceso de abstracción científica, generalizando sobre la base de lo fundamental. 
- Realiza una recopilación adecuada de datos que permiten redescubrir hechos, sugerir problemas, orientar hacia otras fuentes de investigación, orientar formas para elaborar instrumentos de investigación, elaborar hipótesis, etc.

- Puede considerarse como parte fundamental de un proceso de investigación científica, mucho más amplio y acabado.

- Es una investigación que se realiza en forma ordenada y con objetivos precisos, con la finalidad de ser base a la construcción de conocimientos.

- Se basa en la utilización de diferentes técnicas de: localización y fijación de datos, análisis de documentos y de contenidos.

Así, en un sentido restringido, se entiende a la investigación documental como un proceso de búsqueda realizado a través de fuentes impresas (documentos escritos).

Mientras que el Documental, corresponde al estudio de problemas con el propósito de ampliar y profundizar el conocimiento de su naturaleza con apoyo principalmente en trabajos previos, información y datos divulgados por medios impresos, audiovisuales o electrónicos.

Kerlinger (2010) señala que en los estudios documentales "se estudia documentalmente una situación social o institucional para luego estudiar las relaciones entre las actitudes, valores, percepciones y comportamiento de las variables involucrados en dichas situaciones" (p.35).

En este contexto, Hernández; Fernández y Baptista (2009) realizaron una investigación documental basada en el desarrollo de procedimientos basados en la representación de la información, que aportan el conocimiento y la trascendencia de la interpretación del documento, que, a su vez, tiene como objetivo estudiar los fenómenos a lo largo del tiempo.

\section{PROCEDIMIENTO DE LA INVESTIGACIÓN DOCUMENTAL}

RC: 91661

Disponível em: https://www.nucleodoconhecimento.com.br/psicologiaes/personalidad-psicopatica 
Se realiza a través de la detección de las fuentes primarias, secundarias y terciarias, así como también la obtención de la literatura en biblioteca e internet. Se realizo la selección y extracción de la información, a través de las técnicas apropiadas.

La adopción de una teoría o desarrollo de una perspectiva teórica: Comentar aquí la(s) principal(es) teoría(s) contenidas en el marco referencial, o contexto legal que sustente la investigación.

Se ejecutaron las acciones investigativas correspondientes al trabajo documental: Elaboración de la conclusión sobre la posible relación entre los temas estudiados.

\section{TÉCNICAS E INSTRUMENTOS DE RECOLECCIÓN DE INFORMACIÓN}

Arias (2014) define las técnicas e instrumentos de recolección de datos como "las distintas formas y maneras de obtener la información. (p.53). La Forma de recolección de los datos son los siguientes medios:

Técnica de la Revisión Documental: Es una técnica en la cual se recurre a información escrita, ya sea bajo la forma de datos que puedan haber sido producto de mediciones hechas por otros, o como textos que en sí mismos constituyen los eventos del estudio.

\section{ANÁLISIS DE CONTENIDO}

Las consideraciones desarrolladas hasta el momento actua, nos permiten visualizar el desafío hermenéutico (en su perspectiva analítica), el cual está concentrado en la generación del entendimiento. Tomando el enfoque de Echeverría, la pregunta rectora del proceso es cómo generar comprensión. La respuesta a dicha interrogante queda plasmada en las líneas siguientes:

Todo entendimiento, para ser posible, requiere de un preentendimiento tanto en lo que se refiere al medio (lenguaje), como

RC: 91661

Disponível em: https://www.nucleodoconhecimento.com.br/psicologia- 
a la materia del discurso. El reconocimiento de que el entendimiento requiere de un preentendimiento (de un entendimiento previo compartido) es uno de los rasgos fundamentales del círculo hermenéutico (ECHEVERRÍA, 1997, p. 220).

En este sentido, a través de la hermenéutica, se pretende comprender los textos a través de la práctica interpretativa intencional y contextual.

En palabras de Martyniuk (1994), se podría decir que con el abordaje de la hermenéutica en la tesis doctoral se persigue: "romper con elementos simbólicos contenidos en la cultura, romper con las interpretaciones del mundo que se ha construido o heredado". (p. 96)

\section{ANALISIS Y PROSPECTIVA}

Cuadro N². Analisis sobre la Categoría Rasgos de incipiente Psicopatía Infantil.

Severos problemas de conducta, mentiras frecuentes, crueldad con animales 0 destrucción de la propiedad privada son algunos de los rasgos en la niñez que pueden representar un problema de psicopatía en una persona cuando llega a la juventud o adultez.

Así indicó Cecilia Eguiguren Li, directora del hospital Víctor Larco Herrera, especializado en salud mental. Precisó que si bien esos rasgos no son determinantes para señalar con certeza que se está frente a una persona psicopática, los padres 
deben estar alerta si los observan en sus hijos.

"El psicópata se caracteriza por la falta de expresión de afectos y de empatía con el prójimo, no le afecta el dolor ajeno, guarda rencor por cualquier motivo: una pelea o discusión con familiar o con amigos para dar muestra de una conducta agresiva sin medir las consecuencias", señala la especialista.

Agregó que las personas con personalidad psicopática en ocasiones tienen una mala interpretación del trato que consideran se les debe dar porque creen que se merecen todo y que todo es primero para ellos.

"Muchas veces esta conducta se forma cuando los padres optan por los extremos en la formación de sus hijos o hijas: o son muy rígidos, castigadores y privan de cosas con ellos, 0 son muy permisivos, sobreprotectores y satisfacen todos los caprichos", mencionó.

Eguiguren Li recomendó a los padres evitar estas situaciones extremas y mantener la autoridad como padre o 
madre, con premios o sanciones para los hijos/as cuando realmente se merecen premio o castigo.

"Si se porta bien o cumple con sus deberes es bueno recompensar su esfuerzo y conducta, por el contrario, si hace algo que amerita sanción los padres deben ser firmes y hacerles saber que cuando las cosas no se hacen de manera correcta hay consecuencias. En ningún caso se debe recurrir a la violencia", sentenció. Asimismo, dijo que si los padres sienten que no puede manejar la situación deben acudir a un especialista en salud mental para recibir la ayuda necesaria.

Fuente: Propia (2021)

Cuadro №3: Analisis sobre la Categoría Evidencia Clinica de Psicopatía Infantil.

Mucho se ha debatido sobre si el psicópata nace o se hace, una de las pruebas más fehacientes sobre la primera hipótesis son los casos que nos encontramos de psicopatía infantil. La evidencia científica y clínica indica que la mayor parte de las personas 
diagnosticadas como psicópatas comienzan a manifestar rasgos de personalidad característicos de este trastorno a una edad muy temprana.

La psicopatía no surge de repente, sin manifestarse previamente, en la edad adulta. $Y$ las características que la definen algunas veces se muestran ya en los primeros años de vida; al igual que lo que sucede con la mayoría de los trastornos que son diagnosticados en adultos, la investigación revela que la psicopatía es un síndrome que consiste en un conjunto estable de rasgos de personalidad, actitudes y comportamientos desadaptativos que tienen su origen en la infancia, con casos en niños de entre 6 y 10 años.

Los niños que tienen predisposición a desarrollar una psicopatía adulta se mostrarán más egocéntricos e inflexibles en sus exigencias ante sus padres o el resto de personas. No cederán porque sí, lo harán motivados por una amenaza de castigo, aunque siempre intentarán salirse con la suya. Este egocentrismo se incrementará conforme crezcan. A causa del 
destacado interés en su propia persona, estos niños muestran a menudo explosiones coléricas y ataques de rabia. No soportan que les contradigan.

En todos los niños, las emociones innatas o primarias como la sorpresa, la ira, el miedo, la curiosidad, etc, serán evidentes casi desde el nacimiento, y así, los niños más pequeños son capaces de mostrar sus emociones. La ausencia de la expresión emocional puede interpretarse como una predisposición al desarrollo de la psicopatía.

Los niños aprenden la empatía a través del proceso de socialización. Los padres y otros adultos hacen que el menor vaya observando de qué modo sus acciones afectan a los demás. No obstante, estos niños parece que tienen muchas dificultades para admitir que los sentimientos ajenos deben tomarse en cuenta.

Su falta de empatía es la puerta hacia la crueldad. Pueden torturar a los animales domésticos, y molestar a sus amigos y/o hermanos. Se entiende 
que, realmente, no les importa lo que les pueda suceder a los demás, incluyendo sus seres "más queridos".

Desde muy pequeños empiezan a mentir, engañar y manipular. Además, realizan estas conductas con mucha convicción

Por otro lado, si en alguna ocasión se les descubre mintiendo, carecen de nerviosismo e incluso pueden llegar a negarlo todo. La mayoría de instrumentos que evalúan la psicopatía consideran la mentira persistente, a lo largo de todo el desarrollo infantil, como un síntoma importante de este trastorno.

Puede parecer desconcertante etiquetar a niños con esta 'patología', pero la realidad es que existe un síndrome con unos rasgos de personalidad y unas características que advierten problemas a largo plazo, independientemente de cómo le llamemos. Los jóvenes con estas características deben tener especial atención por parte de los especialistas para intentar evitar, en lo posible, futuros comportamientos violentos. 
Fuente: Propia (2021)

\section{CONCLUSIONES Y LINEAS DE TRABAJO FUTURAS}

Tras el desarrollo de esta revisión, se verificaron aportes muy valiosos al estudio de la psicopatía infantil-juvenil, donde ya se han desarrollado instrumentos para la evaluación de jóvenes infractores en el trabajo de Hare, mientras que otros autores han avanzado aún más en este ciclo evolutivo de estudios, en un intento de identificar los antecedentes de la psicopatía.

Para Lynam la concurrencia entre trastorno de conducta e hiperactividad es el antecedente de la psicopatía, para Frick esta coocurrencia es el antecedente de una categoria mis amplia: el atrastorno antisocial de la personalidad. Los origenes especificos de la psicopatia están en un subgrupo de niños con trastorno de conducta, hiperactividad y ademas dureza/insensibilidad.

Sin embargo, la propuesta de Frick merece una atención especial, en vista de su definición de psicopatía (la de Hare) que, desafiando las propuestas más conductuales del DSM, y anclándose en las concepciones clinicas más tradicionales de la psicopatia, ha mostrado su validez en muy diferentes estudios y ha mostrado su utilidad en contextos clinicos y forenses. Cualquier intento por apresar el concepto de psicopatia no debiera prescindir, a nuestro entender, de las caracteristicas emocionales e interpersonales que los clinicos han descrito repetidamente en la figura del psicópata. Limitar la definición de la psicopatia a un estilo de comportamiento antisocial e impulsivo supone empobrecer el constructo, privándolo de sus rasgos más discriminativos y predictivos.

La propuesta de Lynam parece alinearse conceptualmente con la descripción de la psicopatia/trastorno antisocial que el DSM se ha dotado en la última década, presentando las mismas limitaciones que la descripción de conductas impulsivas y personalidad antisocial, pero su concepción no logra comprender 10 más esencial del constructo. A pesar de esto, se sabe que la propuesta de Frick ha de seguir

RC: 91661

Disponível em: https://www.nucleodoconhecimento.com.br/psicologiaes/personalidad-psicopatica 
depurándose y solventado algunos puntos débiles irnportantes, antes de que podamos proponer al PSD como un instrumento definitivo para el diagnóstico de la psicopatia infantil, y antes de que el modelo en su conjunto pueda ser aceptado.

De momento, creemos que la propuesta de Frick bsado en la teoría de Hare es, cuando menos, prometedora, y que merece ser explorada en todas sus dimensiones por parte de los investigadores interesados en los antecedentes evolutivos de un trastorno que, como la psicopatia, genera costes humanos y sociales tan arnplios.

\section{REFERENCIAS BIBLIOGRÁFICAS}

ACHENBACH, T.M. (1991). The Child Behavior Checklist-1991. Burlington: University of Vermont.

ACHENBACH, T.M., CONNERS, C.K., QUAY, H.C., VERHULST, F.C. \& HOWELL, C.T. (1989). Replication of empirically derived syndromes as a basis for taxonomy of child/adolescent psychopathology. Jourtzal of Abnorttlal Child Psychology, 17,299323.

AF KLINTEBERG, B. (1996). The psychopathic personality in a longitudinal perspective. European Child and Adolescent Psychiatry, 5, 57-63.

ALUJA, A. (1989). Psicopatia versus trastorno antisocial de la personalidad: Estudio comparativo. Revista de Psicologia Universitas Tarraconensis, XI, 6-27.

ALUJA, A. (199 1). Personalidad desinhibida, agresividad y conducta antisocial. Barcelona: PPU.

BARBAREE, H., SETO, M., SERIN, R., AMOS, N. \& PRESTON, D. (1994). Comparisons between sexual and nonsexual rapist subtypes. Criminal Justice and Behavior, 21,95-I 14.

RC: 91661

Disponível em: https://www.nucleodoconhecimento.com.br/psicologiaes/personalidad-psicopatica 
BARRY, C.T., FRICK, P.J., DESHAZO, T.M., MCCOY, M.G., ELLIS, M. \& LONEY, B.R. (2000). The importance of callous-unemotional traits for extending the concept of psychopathy to children. Journal of Abnormal Psychology, 109,335-340.

BURKE, H.C. \& FORTH, A.E. (1996). Psychopathy and fanlilial experiences as antecedents to violence: A crosssectional study of young offenders and notzoffending youth. Manuscrito no publicado.Universidad de Carleton, Onawa, Ontario, Canadá.

CAPUTO, A.A., FRICK, P.J. \& BRODSKY, S.L. (1999). Family violence and juvenile sex offending: The potential mediating role of psychopathic traits and negative attitudes toward women. Criminal Justice and Behavior, 26,338-356.

CECILE M, ORTIGUES E. (1987) Cómo se decide una psicoterapia de niños. Buenos Aires. Gedisa.

CHANDLER, M. \& MORAN, T. (1990). Psychopathy and moral developement: A comparative study of delinquent and nondelinquent youth. Development and Psychopathology, 2,227-246.

CHRISTIAN, R.E., FRICK, P.J., HILL, N.L., TYLER, L. \& FRAZER, D.R. (1997). Psychopathy and conduct problems in children: 11. Implications for subtyping children with conduct problems. Joumal of the American Academy of Child and Adolescent Psychiatry, 36,233-241.

CLECKLEY, H (1988). The mask of sanity. St.Louis.

CLECKLEY, H. (1941). The mask of sanity. St. Louis: Mosby.

COOKE, D.J. \& MICHIE, C. (1999, Julio). A hierarchical model ofpsychopathy: Replication and implications for measurement. Ponencia presentada en The eirst Joint APLSIEAPL Psychology and Law International Conference. Dublín, Irlanda. 
E., FORTH, A.E., HART, S.D., Hultermann, J., Woody, G. \& Frances, A. (1996). DSM-IV antisocial personality disorder field trial. Journal of Abnormal Psychology, 105, 3-16.

EN D.J. COOKE, A.E. FORTH \& R.D. HARE (Eds.), Psychopathy: Theory, research and implications for society (pp. 205-230). London: Kluwer.

ERIKSON, E.H. (1968). Identity, youth and crisis. New York.

FARRINGTON, D.P., LOEBER, R., ELLIOTT, D.S., HAWKINS, D.J., KANDEL, D.B., KLEIN, M., MCCORD, J., ROWE, D. \& FARRINGTON, D.P., OHLIN, L.E. \& WILSON, J.Q. (1986). Understanding and conrrolling crime: Toward a new research strategy. New York: Springer-Verlag.

FORTH, A.E. \& BURKE, H.C. (1998). Psychopathy in adolescence: Assessment, violence, and developmental precursors.

FORTH, A.E. (1995). Psychopathy and young offenders: Prevalence, jamily background, and violence. Informe Técnico. Ottawa, Ontario, Canadá: Minister of the Solicitor General of Canada.

FORTH, A.E., HART, S.D. \& HARE, R.D. (1990). Assessment of psychopathy in male young offenders. Psychological Assessment, 2, 342-344.

FORTH, A.E., KOSSON, D.S. \& HARE, R.D. (1994). The Psychopathy Checklist: Youth Version. Manual no publicado, Universidad de Carleton, Ottawa, Ontario, Canadá.

FOWLES, D.C. (1980). The three arousal model: Implications of Gray's two-factor learning theory for heart rate, electrodermal activity, and psychopathy. Psychophysiology, 17, 87-104.

FREUD S. (1974) Más allá del principio del placer. Madrid, Biblioteca Nueva 
FRICK, P.J. \& ELLIS, M. (1999). Callous-unemotional traits and subtypes of conduct disorder. Clinical Child and Family Psychology Review, 2, 149-168.

FRICK, P.J. (1998). Callous-unemotional traits and conduct problems: Applying the two- factor model of psychopathy to children. En D.J. Cooke, A.E. Forth \& R.D. Hare (Eds.), Psychopathy: Theory, research and implications for society (pp. 161-188). London: Kluwer.

FRICK, P.J., BARRY \& BODIN (2000). Applying the concept of psychopathy to children: Implications for the assessment of antisocial youth. En C.B. Gacono (Ed.), The clinical and forensic assessment of psychopathy: A practicioners guide (pp. 324). Hillsdale, NJ: Erlbaum.

FRICK, P.J., BODIN, S.D. \& BARRY, C.T. (2000). Psychopathic traits and conduct problems in community and clinic-referred samples of children: Further development of the Psychopathy Screening Device. Psychological Assessment, 12,382-393.

FRICK, P.J., LILIENFELD, S.O., ELLIS, M., LONEY, B. \& SILVERTHORN, P. (1999). The association between anxiety and psychopathy dimensions in children. Journal of Abnormal Psychology, 27,383-392.

FRICK, P.J., O'BRIEN, B.S., WOOTON, J.M. \& MCBURNETT, K. (1994). Psychopathy and conduct problems in children. Journal of Abnortnal Psychology, 103,700-707.

GORENSTEIN, E.E. (1982). Frontal lobe functions in psychopaths. Journal of Abnormal Psychology, 91, 368-379.

GREEN, S.M. (1993). A sensation-seeking scale for children: A further refinement and psychometric development. Journal of Psychopathology and Behavioral Assessment, 15,69-86.

HARA, R.D. (2003). The hare psychopathy checklist revised. Toronto 
HARE, R..D., MCPHERSON, L.E. \& FORTH, A.E. (1988). Male psychopaths and their criminal careers. Journal of Consulting and Clinical Psychology, 56,710-714.

HARE, R.D. (1980). A research scale for the assessment of psychopathy in criminal populations. Personality and individual Dzrerences, 1, 11 1-1 19.

HARE, R.D. (1991). The Psychopathy Checklist-Revisted. Toronto, Ontario: MultiHealth Systems.

HARE, R.D. (1998). The Alvor Advanced Study Institute. En D.J. Cooke, A.E. Forth \& R.D. Hare @ds.), Psychopathy: Theory, research and implications for society (pp. 111). London: Kluwer.

HARE, R.D., HART, S.D. \& HARPUR, T.J. (1991). Psychopathy and the DsM-Iv criteria for antisocial personality disorder. Journal ofAbnormal Psychology, 100, 391398.

HARE, R.D., WILLIAMSON, S.E. \& HARPUR, T.J. (1988). Psychopathy and language. En T.E. Moffitt y S.A. Mednick (Eds.), Biological contributions to crime causation (pp. 68-92). Dordrecht, Holanda: Martinus Nijhoff.

HARE, R.D: (1993). Without conscience. London: Warner.

HARPUR, T..J., HART, S.D. \& HARE, R.D. (1993). Personality of the psychopath. En P.T. Costa \& T.A. Widiger (Eds.), Personality disorders and thefive-füctor model of personality (pp. 149-173). Washington, DC: American Psychological Association.

HARPUR, T.J., HARE, R.D. \& HAKSTIAN, A.R. (1989). Two-factor conceptualization of psychopathy: Construct validity and assessment implications. Psychological Assessment, I, 6-17.

HARRIS, G.T., RICE, M.E. (2006). Treatment of psychopathy: a review of empirical findings. New York. 
HART, S.D. \& HARE, R.D. (1989). Discriminant validity of the Psychopathy Checklist in a forensic psychiatric population. Psychological Assessment, I, 21 1-218.

HART, S.D. \& HARE, R.D. (1997). Psychopathy: Assessment and association with criminalconduct. En D.M.

HART, S.D. (1998). Psychopathy and risk for violence. En D.J. Cooke, A.E. Forth \& R.D. Hare (Eds.), Psychopathy: Theory, research and implications for society (pp. 355-374). London: Kluwer.

KAZDIN, A.E. \& BUELA-CASAL, G. (1994). Conducta antisocial: Evaluación, tratamiento y prevención en la infancia y adolescencia. Madrid: Pirámide.

KOCHANSKA, G. (1997). Multiple pathways to conscience for children with different temperaments: from toddlerhood to age 5. Developmental Psychology.

KRUH, LP., FRICK, P.J. \& CLEMENTS, C.B. (1999). Predictors of violence commited byjuveniles tried as adults. Manuscrito no publicado.

LACAN J. (1978) Nota sobre el niño. El Analiticón N³ 3. Barcelona 16. Lacan J. Los cuatro conceptos fundamentales del psianálisis. Barcelona. Paidós

LAHEY, B.B., PIACENTINI, J.C., MCBURNETT, K., STONE, P., HARTDAGEN, S. \& HYND, G. (1987). Psychopathology in the parents of children with conduct disorder and hyperactivity. Journal of the American Academy of Child and Adolescent Psychiatry, 27, 163-170.

LAROCHE, I. \& TOUPIN, J. (1996, Agosto). Psychopathic delinquents: A family contribution? Comunicación presentada en el XXVI International Congress of Psychology, Montreal, Canadá.

LAURENT E. EI niño y su madre. El Analiticón n 1. Barcelona 1986.

RC: 91661

Disponível em: https://www.nucleodoconhecimento.com.br/psicologiaes/personalidad-psicopatica 
LILIENFELD, S.O. \& ANDREWS, B.P. (1996). Development of a preliminary validation of a self-report measure of psychopathic personality traits in noncriminal populations. Joumal of Personality Assessment, 66, 488-524.

LOEBER, R. \& DISHION, T.J. (1983). Early predictors of male adolescent delinquency: A review. Child Development, 53, 1431-1446.

LOEBER, R. (1988). Behavioral precursors and accelerators of delinquency. En W. Buikhuisen \& S.A. Mednick (Eds.), Explaining criminal behavior (pp. 51-67). Leiden, NY: Brill.

Loeber, R., Brinthaupt, V.P. \& Green, S. (1990). Attention deficits, impulsivity, and hyperactivity with or without conduct problems: Relationships to delinquency and unique contextual factors. En R.J. McMahon \& R.D. Peters (Eds.), Behavior disorders of adolescence: Research, intervention, andpolicy in clinical and school settings (pp. 39-61). New York: Plenum.

LONEY, B.R., FRICK, P.J., ELLIS, M. \& MCCOY, M.G. (1998). Intelligence, callousunemotional traits, and antisocial behavior. Joumal of Psychopathology and Behavioral Assessment, 20,23 1-247.

LOSEL, F. (1998). Treatment and management of psychopaths. En D.J. Cooke, A.E. Forth \& R.D. Hare (Eds.), Psychopathy: Theory, research and implications for society (pp. 303-354). London: Kluwer.

LUENGO, M.A. Y CARRILLO, M.T. (1995). La psicopatia. En A. Belloch, B. Sandin y F. Ramos (Eds.), Manual de psicopatologíu (pp. 615-647). Madrid: McGraw Hill.

LYKKEN, D.T. (1957). A study of anxiety in the socipathic personality. Journal ofAbnorma1 and Social Psychology, 55.6- 10.

LYKKEN, D.T. (1995). The antisocial personalities. Hillsdale, New Jersey: Erlbaum.

RC: 91661

Disponível em: https://www.nucleodoconhecimento.com.br/psicologiaes/personalidad-psicopatica 
LYNAM, D. R. (1998). Early identification of the fledgling psychopath: Locating the psychopathic child in the current nomenclature. Journal of Anormal Psychology

LYNAM, D.R. (1996). Early identification of chronic offenders: Who is the fledgling psychopath? Psychological Bulletin, 120, 209-234.

LYNAM, D.R. (1997). Pursuing the psychopath: Capturing the fledgling psychopath in a nomological net. Journal of Abnormal Psychology, 106,425-438.

LYNAM, D.R. (1998). Early identification of the fledgling psychopath: Locating the psychopathic child in the current nomenclature. Journa1 of Abnormal Psychology, 107,566-575.

MANNONI M. El niño retardado y su madre. Buenos Aires, Paidós 1982.

MCBRIDE, M.E. \& HARE, R.D. (1996). Precursors ofpsychopathy and recidivism. Manuscrit0 no publicado, Universidad de British Columbia, Vancouver, Canadb.

MCBURNETT, K. \& PFIFFNER, L. (1998). Comorbidities and biological correlates of conduct disorder. En D.J. Cooke, A.E. Foah \& R.D. Hare (Eds.), Psychopathy: Theory, research and implications for society (pp. 189-204). London: Kluwer.

MCGEE, R., SILVA, P.A. \& WILLIAMS, S. (1984). Behavior problems in a population of seven-year-old children: Prevalence, stability, and types of disorder. A research note. Journal of Child Psychology and Psychiatry, 25,251-259.

MILICH, R.S., HARTUNG, C., MARTIN, C. \& HAIGLER, E. (1994). Behavioral disinhibition and underlying processes in adolescents with disruptive behavior disorders. En D.K. Routh (Ed.), Disruptive behavior disorders in childhood (pp. 109138). New York: Plenum.

RC: 91661

Disponível em: https://www.nucleodoconhecimento.com.br/psicologiaes/personalidad-psicopatica 
MILLON, T. \& DAVIS, R.D. (1998). Ten subtypes of psychopathy. En T. Millon, E. Simonsen, M. Birkett-Smigh \& R.D. Davis (Eds.), Psychopathy: Antisocial, criminal, and violent behavior (pp. 161-160). New York: Guilford.

MOFFITT, T.E. (1993). Adolescence-limited and life-course-persistent antisocial behavior: A developmental taxonomy. Psychological Review, 100,674-701.

MOLTÓ, J., POY, R. \& TORRUBIA, R. (2000). Standardization of the Hare Psychopathy Checklist-Revised in a Spanish prison sample. Joumal of Personality Disorders, 14, 84-96.

NEWMAN, J.P. \& WALLACE, J.F. (1993). Psychopathy and cognition. En P.C. Kendall \& K. S. Dobson (Eds.), Psychopathology and Cognition (pp. 293-349). New York: Academic Press.

NEWMAN, J.P., WIDOM, C.S. \& NATHAN, S. (1985). Passive avoidance in syndromes of disinhibition: Psychopathy and extroversion. Journal of Personality and Social Psychology, 48, 1316-1327.

O'BRIEN, B.S. \& FRICK, P.J. (1995). Reward dominance: Associations with anxiety, conduct problems, and psychopathy in children. Journal of Abnormal Child Psychology, 24,223-240.

O'BRIEN, B.S., FRICK, P.J. \& LYMAN, R.D. (1994). Reward dominance in children with disruptive behavior disorders. Journal of Psychopathology and Behavioral Assessment, 16, 131-145.

ORGANIZACIÓN - MUNDIAL DE LA SALUD (OMS) (19921. Clasificacidn internacional de las enfemedades mentales (10" ed.). Madrid: OMS.

PATRICK, C.J. (1994). Emotion and psychopathy: Startling new insights. Psychophysiology, 31,319-330. 
PATTERSON, G.R., REID, J.B. \& DISHION, T.J. (1992). Antisocial boys. Eugene, OR: Castalia. Quav. - H.C. (1987). Pattems of delinauent behavior. En H.C. Ouav (Ed.). Handbook of iuvenile delinaliencv (DD. .. - .. .. "e A ..*\& 118-138). New York:

QUAV. H.C. -. (1999). Classification of the dism tive behavior disorders. En H.C. Ouav \& A.E. Honan -. (Eds.). , andbook of disruptive behavior diso;ders (pp. 3-21). New York: luwerRaine,

RAINE, A. (1999, noviembre). Psicopatia, violencia y neuroimágenes. Ponencia presentada en el seminario a Psicópatas y asesinos en serie* Valencia, Centro Reina Sofia Dara el Estudio de la Violencia.

RAINE, A., M., SMILEY, N., SCERBO, A. \& CHAN, C.J. (1990). educed lateralization in verbal dichotic listening in adolescent psychopaths. Joumal of Abnormal Psychology, 99,272-277.

RICHTERS, J.E. \& CICCHETTI, D. (1993). Toward a developmental perspective on conduct disorder. Developrnent and Psychopathology, 5, 1-4.

ROBINS, L.N. (1966). Deviant children grown up. Baltimore: Williams \& Wilkins. $\backslash$ El constructo psicopatia en la infancia y la adolescencia

ROMERO ESTRELLA (2012) El constructo psicopatia en la infancia y la adolescencia: del trastorno de conducta a la personalidad antisocial. Universidad de Santiago de Compostela.

ROMERO, E. (1998). Teorías sobre delincuencia en 10s 90. Anuario de Psicologia Jurídica, 31-59.

ROMERO, E., LUENGO, M.A. Y GÓMEZ-FRAGUELA (2000). Factores psicosociales y delincuencia: Un estudio de efectos recíprocos. Escritos de Psicologia, 4,78-91. 
ROMERO, E., LUENGO, M.A., \& SOBRAL, J. (2001). Personality and antisocial behaviour: Study of temperamental dimensions. Personality and Individual Differences, 31,329-348

ROMERO, E., SOBRAL, J. Y LUENGO, M.A. (1999). Personalidad y delincuencia: Entre la biologia y la sociedad. Granada: Grupo Editorial Universitario.

ROMERO, E., SOBRAL, J., LUENGO, M.A. \& MARZOA, J.A. (1999, julio). Risk factors ofjuvenile delinquency: Study of interactive effects. Comunicación presentada en The Fust Joint APLS EAPL Psychology and Law Intemational Conference. Dublin, Irlanda.

ROMERO, E., SOBRAL, J., LUENGO, M.A. \& MARZOA, J.A. (2001). Values and antisocial behavior among Spanish adolescents. Journal of Cenetic Psychology, 162,20-40.

RUSSO, M.F., STOKES, G.S., LAHEY, B.B., CHRIST, M.A.G., MCBURNETT, K. LOEBER, R., STOUTHAMER-LOEBER, M. \& RUTTER, M., GILLER, H. \& HAGELL, A. (1998). Antisocial behavior by young people. Cambridge: Cambridge University Press.

SALEKIN, R.T., ROGERS, R. Y SEWELL, K.W. (1996). A review and meta-analysis of the Psychopathy Checklist and Psychopathy Checklist-Revised: Predictive validity of dangerousness. Clinical Psychology: Science and Practice, 3,203-215.

SCERBO, A., RAINE, A., O'BRIEN, M., CHAN, C., RHEE, C. \& SMILEY, N (1990). Reward dominance and passive avoidance learning in adolescent psychopaths. Journal of Abnorma Child Psychology, 18,451-463.

SEAGRAVE, D. GRISSO, T. (2002). Adolescent development and the measurement of juvenile psychopathy. Law and Human Behavior. 
SILVERTHORN, P. \& FRICK, P.J. (1999). Developmental pathways to antisocial behavior: Te delayed-onset pathway in girls. Development andpsychopathology, 11, 101-126.

SILVERTHORN, P., FRICK, P.J. \& REYNOLDS, R. (1998). Timing of onset and correlates of severe conductproblems in adjudicated girls and boys. Mantlscrito no publicado. Stoff, J. Breiling \& J.D. Maser (Eds.), Handbook of antisocial behavior [pp, 22-35). New York: Toupin, J., Mercier, H., Déry, M., CBté, G. \& Hodgins, S. (1995, Noviembre). Validity of the PCL-R for adolescents. Comunicación presentada en el Instituto de Estudios Avanzados OTAN sobre Psicopatia, Alvor, Portugal.

TREMBLAY, R. (1990). Advancing knowledge about the onset of delinquency and crime. En B. Lahey \& A. Kazdin (Eds.), Advances in clinical childpsychology (vol., 13, pp. 283-342). New York: Plenum.

TREVETHAN, S.D. \& WALKER, L.J. (1989). Hypothetical versus real-life moral reasoning among psychopathic and delinquent youth. Development and Psychopathology, 1.91-103.

WATSON, D. \& CLARK, L.A. (1984). Negative affectivity: The disposition to experience aversive emotional states. Psychological Bulletin, 98,219-235.

WIDIGER, T.A., CADORET, R., HARE, R.D., ROBINS, L., RUTHERFORD, M., ZANARINI, M., ALTERMAN, A., APPLE, M., CORBITT, WILSON, D.L., FRICK, P.J. \& CLEMENTS, C.B. (1999). Gender, somatization, and psychopathic traits in a college sample. Journal of Psychopathology and Behavioral Assessment, 21,221235.

WOOTON, J.M., FRICK, P.J., SHELTON, K.K. \& SILVERTHORN, P. (1997). Ineffective parenting and childhood conduct problems: The moderating role of callous-unemotional traits. Journal of Consulting and Clinical Psychology, 65,301308.

RC: 91661

Disponível em: https://www.nucleodoconhecimento.com.br/psicologiaes/personalidad-psicopatica 
WORK, H. (1994). Child psychiatry: Its emergence and growth in the 20th century. Psychiatric News, 20 mayo.

Enviado: Abril, 2021.

Aprobado: Julio, 2021. 